\title{
Mesocrystals: Inorganic Superstructures Made by Highly Parallel Crystallization and Controlled Alignment
}

Helmut Cölfen* and Markus Antonietti

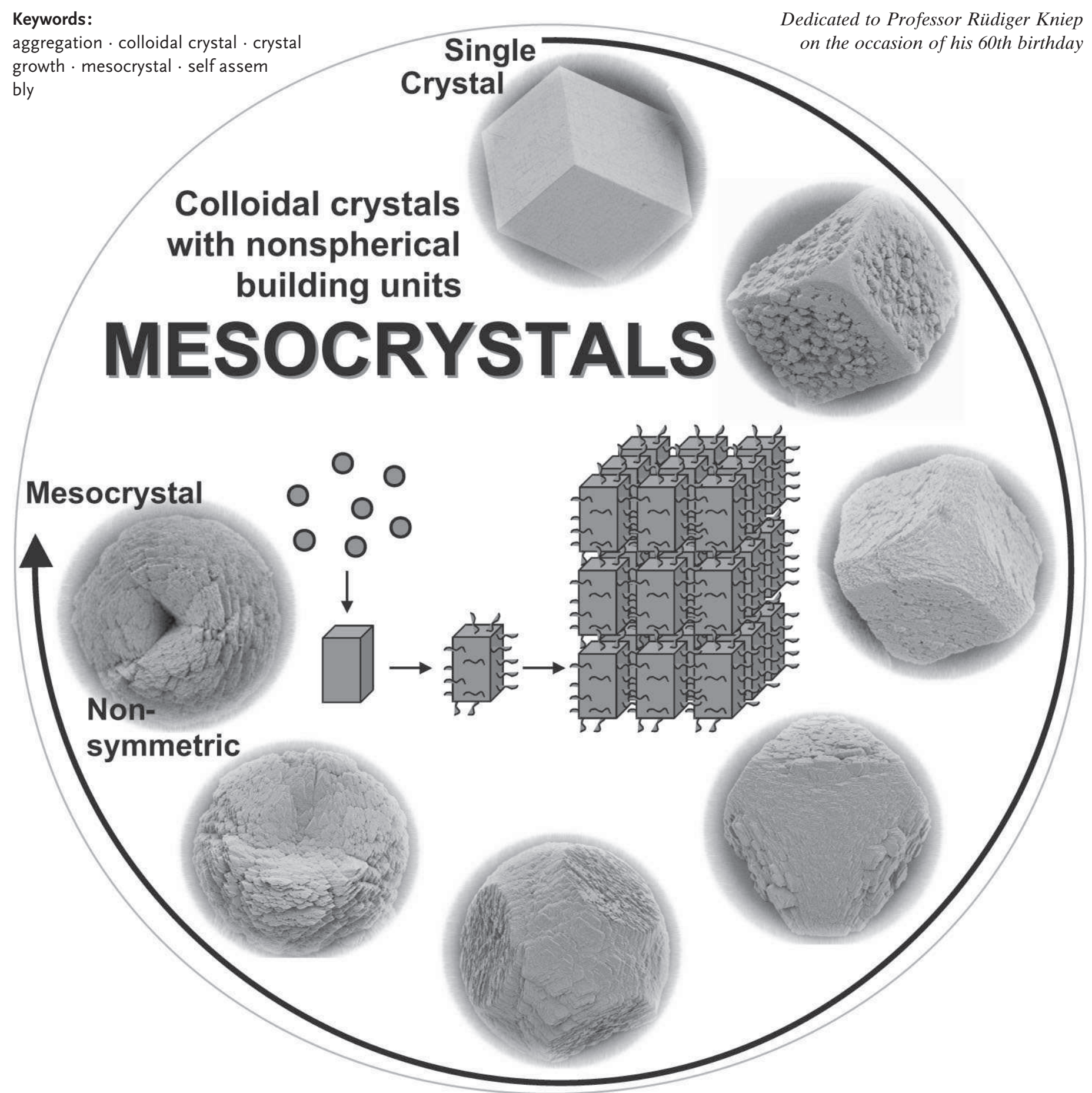


c rials. The colloidal crystallization of non-spherical nanocrystals is a reaction channel in many crystallization reactions. With additives, selforganization can be stopped at an intermediary step-a mesocrystalin which the primary units can still be identified. Mesocrystals were observed for various systems as kinetically metastable species or as intermediates in a crystallization reaction leading to single crystals with typical defects and inclusions. The control forces and mechanism of mesocrystal formation are largely unknown, but several mesocrystal properties are known. Mesocrystals are exiting examples of nonclassical crystallization, which does not proceed through ion-byion attachment, but by a modular nanobuilding-block route. This path makes crystallization more independent of ion products or molecular solubility, it occurs without pH or osmotic pressure changes, and opens new strategies for crystal morphogenesis.

\section{From the Contents}

\begin{tabular}{l} 
1. Introduction \\
2. Early Reports on Mesocrystals \\
\hline $\begin{array}{l}\text { 3. One- and Two-Dimensional } \\
\text { Mesocrystals }\end{array}$ \\
$\begin{array}{l}\text { 4. Three-Dimensional } \\
\text { Mesocrystals }\end{array}$ \\
\begin{tabular}{l} 
5. Conclusions \\
\hline
\end{tabular}
\end{tabular}

although single crystalline, often con tain minor amounts of included biopo lymers. This inclusion is not under standable from the viewpoint of an ion mediated crystallization process,

\section{Introduction}

Alignment of nanoparticle building blocks into ordered superstructures by bottom up approaches is one of the key topics of modern colloid and materials chemistry. ${ }^{[1]}$ In this area, much can be learned from the processes of biominer alization, which lead to well defined organic inorganic hybrid materials with superior materials properties, complex mor phologies. and hierarchical order. ${ }^{[24}$ Biominerals are often single crystals with amazingly complex morphologies such as the hammer shaped building units of coccoliths ${ }^{[5]}$ or the skeletal plates of sea urchins. ${ }^{[6]}$ Although it is known that organic scaffolds, as in the case of coccoliths, play an important role, ${ }^{[5]}$ the actual crystallization mechanism of the inorganic phase remains largely unexplored. Recently, increasing evidence was found that biomineralization takes place through amorphous precursor particles, for example, as reported for sea urchin spines. ${ }^{[7]}$ In this way large amounts of material can be stored in metastable precursor particles, which are readily available to a crystallization event in a confined reaction environment. Further advantages of this crystallization pathway are highly efficient mass fluxes that are independent of solubility products, the coupled high crystallization speeds, and crystallization without change of the $\mathrm{pH}$ value and the osmotic pressure. These are key features for mineralization especially in biological systems. This pathway is in stark contrast to the classical crystallization, which postulates an ion by ion or single molecule attachment to a critical crystal nucleus and is therefore bound to solubility products and diffusion limitations. Mesoscale transformation processes towards crystalline phases were recently reviewed. ${ }^{[8]}$

By mesoscale transformation, not only single crystals with complex morphologies but also superstructures made up of nanoparticles interspaced by organic additives can be formed. The fusion of the building blocks leads to single crystalline structures with included organic additives as defects. Support for this view comes from biomineral examples, which, as additives are generally considered to adsorb at edges and kinks of the developing crystal surface stopping it from further growth. ${ }^{[9]}$

Mesocrystal formation and the process of mesoscale transformation seem, however, not to be limited only to biominerals. It looks like nature only employs this advanta geous physico chemical construction principle, gaining speed and flexibility of construction. For example, similar to biomineralization, inclusions of additives up to $30 \mathrm{wt} \%$ are observed in synthetically grown crystals, too. ${ }^{[10,11]}$ Revisiting the existing literature shows indeed that comparable obser vations have been made in synthetic inorganic chemistry much earlier, even in the absence of additives, ${ }^{[12,13]}$ and the question can be raised if precursor particles and their superstructures also play a role at least as intermediates in crystallization in a much broader context.

In this Review we revisit the existing literature and examine it from the viewpoint of nonclassical, nanoparticle mediated crystallization. A mesocrystal in this context is defined as a superstructure of crystalline nanoparticles with external crystal faces on the scale of some hundred nano meters to micrometers (Figure 1).

Mesocrystal intermediates can also lead by fusion to the formation of single crystals with included organic additives, sometimes allowing the observation of highly oriented nano particle based intermediates. This scenario is shown in Figure 1.

It has to be noted that the term "mesocrystal" has already been used in the literature, but in the less restricted sense of a mutual three dimensional translational order of various nanocrystals. As templates, pore systems of the MCM 41

[*] Dr. H. Cölfen, Prof. Dr. M. Antonietti

Max Planck Institute of Colloids and Interfaces

Colloid Chemistry, Research Campus Golm

14424 Potsdam (Germany)

Fax: (+49) 3315679502

E mail: Coelfen@mpikg.mpg.de 


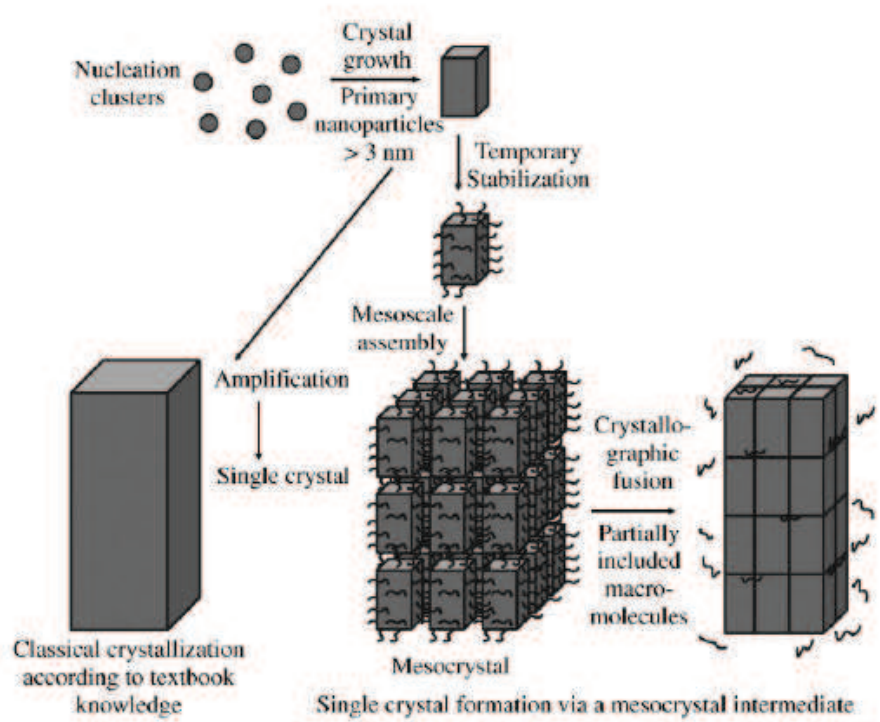

Figure 1. Classical crystallization (left) by ion by ion addition versus single crystal formation by a mesocrystal intermediate formed by nano particle self assembly. Image based upon ref. [8]

type were used for the deposition of size quantized $\mathrm{BaTiO}_{3}{ }^{[14}$ 16] or $\mathrm{SrBi}_{2} \mathrm{Ta}_{2} \mathrm{O}_{9} \cdot{ }^{[15,17]}$ Our definition is more restricted as it also involves orientational order (vectorial alignment) and the self assembly to facetted microstructures.

Mesocrystals are a special case of colloidal crystals. The latter have received considerable attention in recent years, as they result from the formal substitution of atoms or molecules in a classical crystallization event by defined and monodis perse nanoparticles this leads to superlattices with new and desirable properties such as photonic band gaps ${ }^{[18]}$ or altered electronic and optical properties as in the case of semi conductors. ${ }^{[19]}$ In addition to colloidal crystals made from $\mathrm{SiO}_{2}$ which are a convenient model case, semiconductor and metal nanoparticles have been intensively investigated, owing to their electronic and optical applications. ${ }^{[2024]}$ Usually, the nanoparticle building blocks can be regarded as spherical core shell nanoparticles with an inorganic core and an organic surfactant/ligand shell, both of which play a role for the crystallographic symmetry of the superlattice. Even colloidal crystals from two different nanocrystal systems could be prepared. ${ }^{[24]}$ If inorganic and slightly prolate building units such as CdSe were used, an almost perfect crystallo graphic alignment of the nanocrystals was detected ${ }^{[19]}$ a feature which is also observed in mesocrystals as will be discussed later. Nevertheless, colloidal crystals were so far only self assembled from spherical nanoparticles or by covalent linkage of clusters, ${ }^{[2]}$ although it is clear that nonspherical nanoparticle building units should provide additional opportunities for self assembly. Concepts to design such colloidal crystals, for example by orientation of nonspherical nanoparticles through magnetic fields are just being developed, and have to date not been experimentally verified. ${ }^{[26]}$ It is important to remember that the mesocrystals described below already manifest the applicability of such concepts as they consist of highly oriented nonspherical building units and are formed through a pure self assembly approach.

\section{Early Reports on Mesocrystals}

Although particle aggregates have been observed since the advent of crystallization experiments, particle aggregates with defined morphology and size were much less reported. For a Review by one of the pioneers in this field, see ref. [27]. One of the very first indications of mesocrystal intermediates was deduced from the porous internal structure of $\mathrm{BaSO}_{4}{ }^{[28]}$ which according to the classical crystallization theory should crystallize to a defect free single crystal.

First indications of mesocrystals, although without per fectly flat external faces, were reported by Matijevic et al. in a synthetic study on various $\mathrm{Ce}^{\mathrm{IV}}$ compounds in absence of any organic additives ${ }^{[13]}$ Figure 2 shows some of these rod like particles of $\mathrm{Ce}^{\mathrm{IV}}$ minerals.

These structures are clearly nanoparticle aggregates but without a well facetted external morphology. Nevertheless, the single rodlike or platelike nanoparticles mutually align with high positional and vectorial precision to give a reproducible superstructure.

Another example is reported for the same components ${ }^{[3]}$ as well as for $\mathrm{CuO}$, depicted in Figure 3 (right) ${ }^{[29]}$ For $\mathrm{CuO}$, the aggregation from primary nanoparticles could be revealed in a kinetic study which already indicated the general self assembly mechanism for mesocrystals, although a faceting of the nanocrystal aggregates is generally lacking (Figure 3,

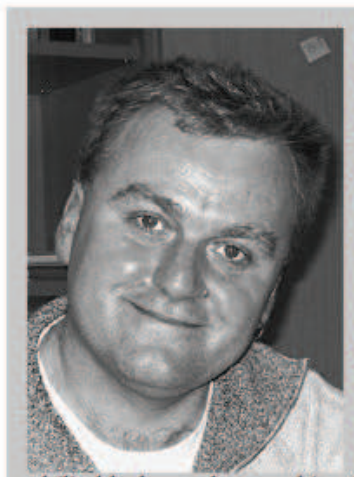

philic block copolymers, biomimetic tallization. In his spare time he plays music in a band.
Helmut Cölfen studied Chemistry at the uni versity Duisburg and completed his PhD in 1993 supervised by Werner Borchard. After a Postdoc at the NCMH Nottingham with Stephen Harding, he joined the Max Planck Institute of Colloids and Interfaces in 1995 and finished his Habilitation on "Biomimetic Mineralization" in 2001 with Markus Anto nietti. He is now a lecturer at the University of Potsdam and head of the analytical sen ice in the colloid chemistry department of the MPI. His current research is focused on the synthesis and analysis of double hydro

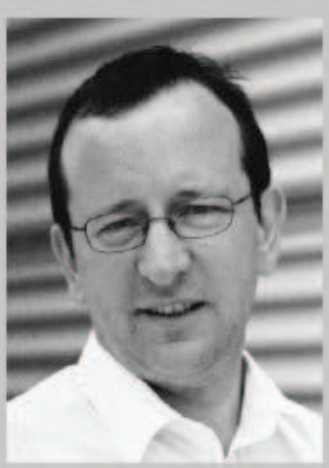
Markus Antonietti studied Chemistry in Mainz and did his doctorate with Hans Sil lescu. His habilitation about nanostructured polymergels in 1990 filled him with enthusi asm for complex materials. After his profes sorship for Chemistry at the University of Marburg he was appointed director for the department of Colloid Chemistry at the Max Planck Institute of Colloids and Interfaces in 1993. His main academic interest is in the creativity in research. He loves to share and impart this passion. He likes cooking with his family and loud music. 

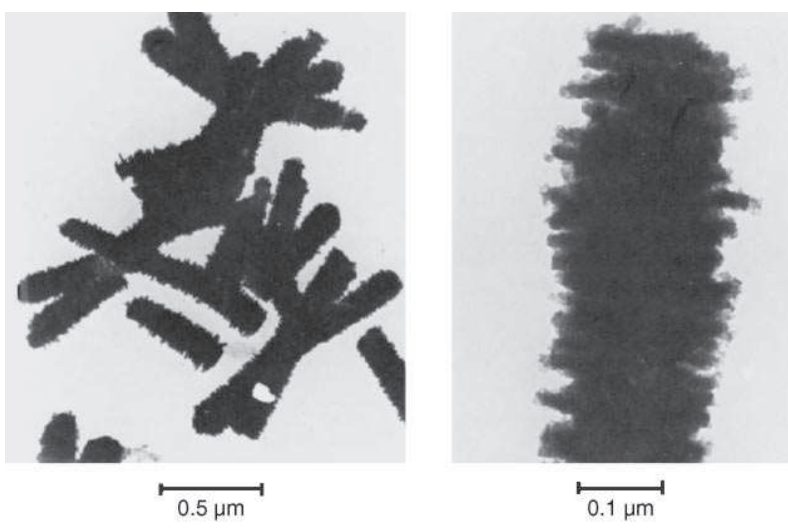

Figure 2. Transmission electron microscope (TEM) images of rodlike $\mathrm{Ce}^{\mathrm{IV}}$ sulfate particles obtained by aging $2.5 \times 10{ }^{9} \mathrm{moldm}{ }^{3} \mathrm{Ce}\left(\mathrm{SO}_{4}\right)_{2}$, $4.5 \mathrm{~mol} \mathrm{dm}{ }^{3} \mathrm{H}_{2} \mathrm{SO}_{4}$, and $0.45 \mathrm{moldm}{ }^{3} \mathrm{Na}_{2} \mathrm{SO}_{4}$ at $90^{\circ} \mathrm{C}$ for $12 \mathrm{~h}$. Figure reproduced from ref. [13] with kind permission of the American Chemical Society.
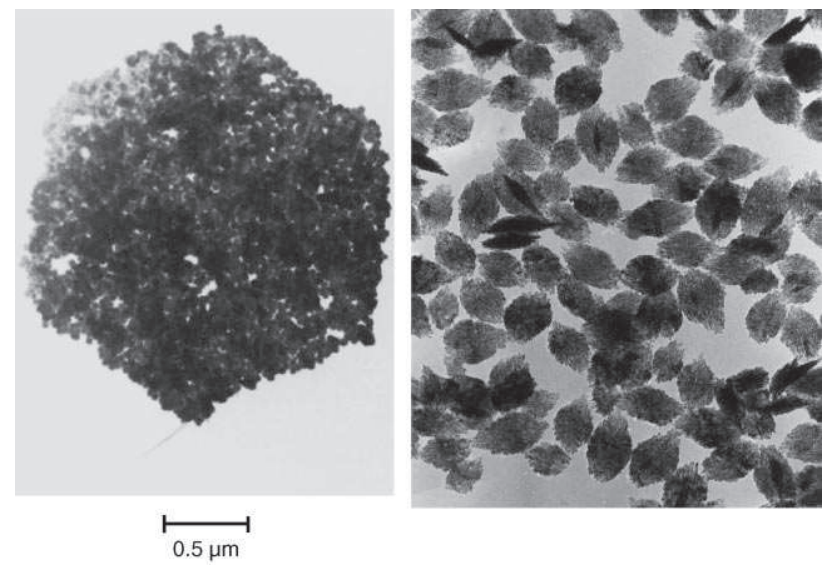

Figure 3. Left: TEM of a minor part of $\mathrm{CeO}_{2}$ precipitates obtained by aging $1.5 \times 10^{3} \mathrm{~mol} \mathrm{dm}{ }^{3}\left(\mathrm{NH}_{4}\right)_{2}\left[\mathrm{Ce}\left(\mathrm{NO}_{3}\right)_{6}\right], 6.4 \times 10^{2} \mathrm{~mol} \mathrm{dm}^{3}$ $\mathrm{H}_{2} \mathrm{SO}_{4}$, and $1.6 \times 10^{2} \mathrm{moldm}{ }^{3} \mathrm{Na}_{2} \mathrm{SO}_{4} \mathrm{pH} 1.4$ at $90^{\circ} \mathrm{C}$ for $12 \mathrm{~h}$. Figure reproduced from ref. [13] with kind permission of the American Chemi cal Society. Right: CuO particle aggregates obtained via double jet pre cipitation, ${ }^{[29]}$ reproduced with permission from Academic Press.

right). For $\mathrm{CeO}_{2}$, a two dimensional hexagonal platelet is formed from not very homogeneous and not very well defined spherical nanoparticles (Figure 3, left). Clearly, the mutual interaction forces drive the single nanoparticles to form a hexagonal superstructure. It is remarkable that $\mathrm{CeO}_{2}$ possesses a primitive triclinic unit cell, that is, it has especially no hexagonal symmetry axis. It will be shown below that mesocrystals very often have a higher symmetry than their constituting tectons. This occurrence is speculatively assigned to multiple twinning of primitive units and the resulting symmetry average on the mesoscale. ${ }^{[30]}$ In these early experi ments, the hexagon superstructure however just represented a minor part of the precipitates and its formation mechanism remained as unclear as for the rods shown in Figure 1. Nevertheless, it was an early observation of crystalline superstructures with an external structure and symmetry differing from that of the nanoparticle building units, but with a not too well ordered nanoparticle interior. For the sake of completeness, it should be mentioned that very similar observations on the oriented aggregation of $\mathrm{CuO}$ were just recently published ${ }^{[31]}$ however with a more precise view of the relevant phenomena.

As early as 1986, mesocrystals with even higher definition were reported for $\mathrm{CaCO}_{3}$ made in silica gels. ${ }^{\left[{ }^{[2]}\right.}$ In this case, fibers built from a set of cleaved calcite rhombohedra arranged along their $c$ axis were reported. Although each fiber was an aggregate of crystalline subunits, the observed behavior by polarization microscopy was that of a single crystal indicating the high orientational alignment of the subunits in this one dimensional mesocrystal. ${ }^{[32]}$ Interestingly, these mesocrystal fibers were only an outer part of a hierarchical structure, the so called "sheaf of wheat" mor phology. ${ }^{[32]}$ From different sheaves, mesocrystal fibers with a very different morphology radially splayed out from the sheaf center. Again, the mesocrystals behaved like single crystals in polarization microscopy and exhibited a complicated mor phology (Figure 4). The reason for this unusual aggregate morphology remained unexplained, although the morpho genesis process was assumed to be of importance.

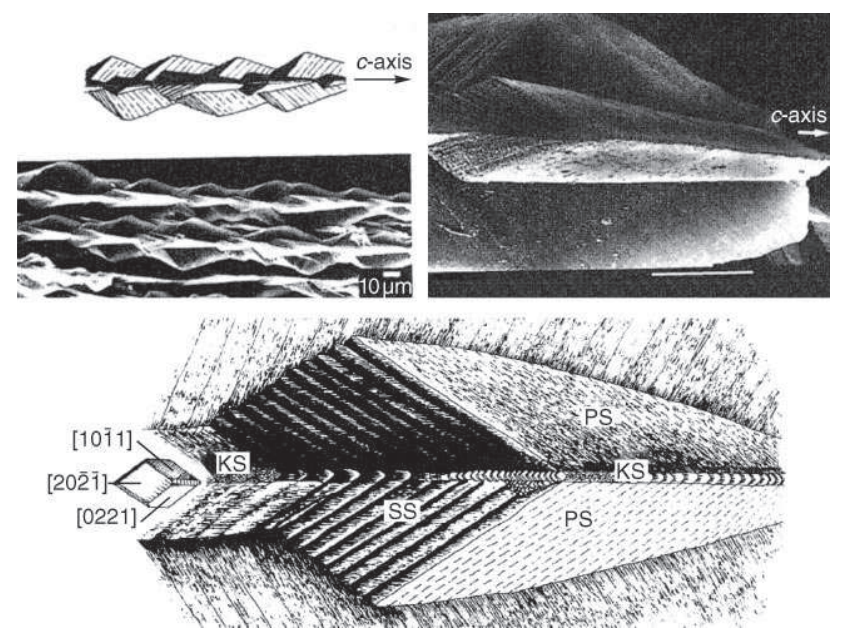

Figure 4. $\mathrm{CaCO}_{3}$ formed in a silica gel. Top left: SEM view of a set of serrated fibers and a diagram of one fiber. Top right: Enlarged view of the left SEM image showing a morphological unit form by two domes (scale bar $10 \mu \mathrm{m}$. Bottom: Diagrammatic representation of a mor phological unit of the structures shown in the top part revealing the orientation of the aggregating rhombohedra. PS planar surfaces, KS kinked surfaces, SS stepped surfaces. Reprinted from ref. [32] with permission of Elsevier Science publishers B.V.

Such work has stimulated experiments where otherwise stable nanoparticles of anatase were destabilized in a controlled fashion, either by hydrothermal treatment ${ }^{[33]}$ or by the addition of face specific organic molecules called "assemblers". ${ }^{[34,35]}$ Indeed, a few years ago, the first nano particle based structuration mechanism was identified. ${ }^{[33]}$ In this so called "oriented attachment", nanoparticles fuse together with their high energy surfaces under crystallo graphic fusion and elimination of the high energy faces under energy gain, thus creating extended structures. ${ }^{[33]}$ Addition of assembler throughout this process even improves the control 
over the aggregation process $;^{[34,35]}$ similar levels of control were also found with polymeric additives. ${ }^{[36}{ }^{39]}$ Such an oriented attachment mechanism was then suggested also to hold true for iron hydroxide biomineralization products. ${ }^{[40]}$

\section{One- and Two-Dimensional Mesocrystals}

One and two dimensional particle arrays such as those shown above were also reported by Mann and co workers but in a difference to the previous studies, they used a surfactant microemulsion mediated approach. In this case, presumably a combined action of nanoparticle crystallization and surfactant interactions led to the self assembly of these remarkable low dimensional structures, and a surfactant mediated aggrega tion mechanism was suggested for the growth of these structures, as shown in Figure 5. ${ }^{[41]}$

The structures shown in Figure 5 quite nicely illustrate some of the building principles of mesocrystals (shown as a sketch in Figure 1) in one or two dimensions: the primary crystalline building blocks are mutually aligned, following common crystallographic coordinates. The structure in itself is not exactly crystalline, as minor differences in length or size are tolerated and taken up in the structure. It is a mutual self organization principle, which can tolerate lattice defects.

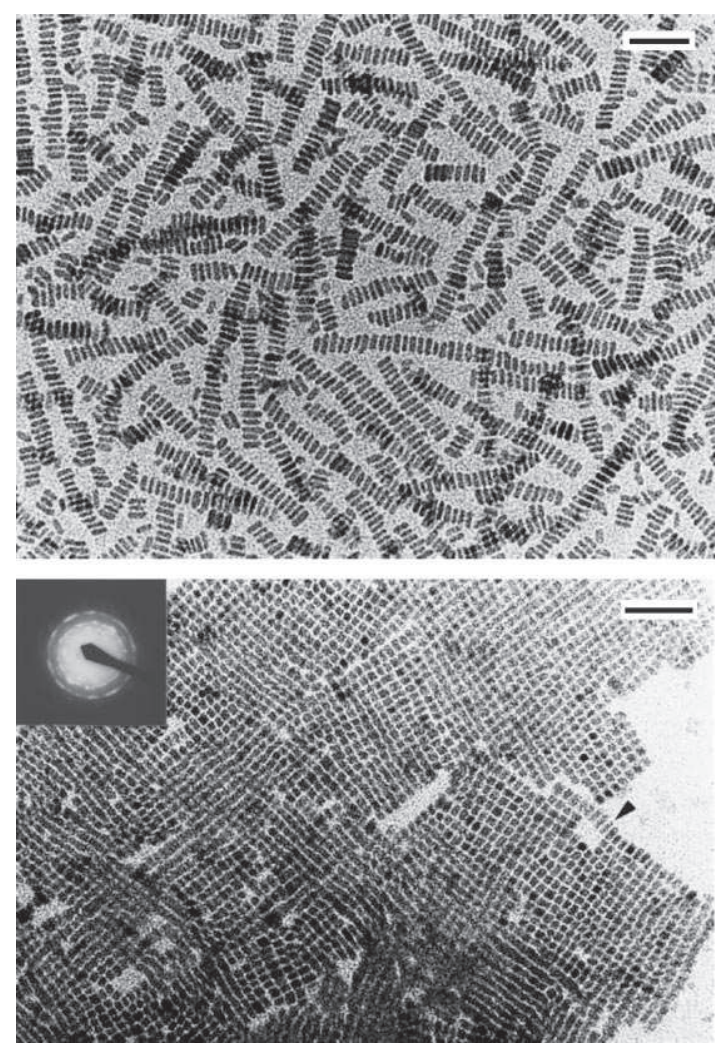

Figure 5. TEM images showing top: ordered chains of prismatic $\mathrm{BaCrO}_{4}$ nanoparticles and bottom: rectangular superlattice of $\mathrm{BaCrO}_{4}$ nanoparticles ${ }^{[41]}$ prepared in a reverse microemulsion. Scale bars $50 \mathrm{~nm}$. The arrow indicates dislodged particles revealing the prismatic morphology of individual crystallites. Inset: The electron dif fraction pattern gives the superimposition of reflections from zone axes approximately parallel to the [100] direction. Reproduced from ref. [41] with kind permission of Nature Publishing Group.

\section{Three-Dimensional Mesocrystals}

Examinations on defined particle aggregation by hydro philic molecules ${ }^{[42]}$ or double hydrophilic block copolymers (DHBCs) as especially powerful surface active agents to control crystallization and superstructure formation of inor ganic compounds, ${ }^{[43]}$ have subsequently multiplied the reported observations of diverse mesocrystal systems. Herein, it will be shown that the restrictions on additive design for mesocrystal formation are not too strict, as even just a preferential attachment to specific surfaces of the primary crystals can lead to strongly anisotropic mutual interactions. Among these interactions, dipole fields were first suggested by Busch, Kniep, et al. to be of importance for the structuration process of inorganic matter..$^{[44,45]}$

The formation mechanisms of three dimensional meso crystals are largely unexplored. One of the difficulties maybe the high lattice energy of inorganic crystals, which in many cases leads to the crystallographic fusion of the oriented nanocrystal building units to a single crystal (Figure 1) through the three dimensional oriented attachment mecha nism. ${ }^{[33]}$ Another difficulty maybe the homogeneous aqueous environment, where it is difficult to predict how hydrophilic nanoparticles can be arranged to defined three dimensional mesocrystals. Herein we will try to reveal a general meso crystal formation mechanism, that is clearly distinguishable from the default case of uncontrolled primary particle aggregation.

One of the first three dimensional mesocrystals and probably the most perfect to date was reported by Busch and Kniep in form of an elongated, hexagonal prismatic fluoroapatite seed crystal formed in a double diffusion experiment at ambient temperature in a gelatine gel (Figure 6). $\left.{ }^{[44} 46\right]$ The hexagonal seed crystal was not directly recognizable as a mesocrystal, as it showed a well facetted, single crystal like morphology (Figure 6). Even $\mathrm{X}$ ray dif fraction showed features of a fluorapatite single crystal oriented along the $c$ axis, ${ }^{[47,48]}$ because of the very high vectorial order of its nanoparticulate building units. Although the hexagonal crystals contain approximately $2 \mathrm{wt} \%$ intra crystalline gelatine, the polymer does not modulate the crystal structure, so it was concluded that the gelatine adapts to the fluoroapatite structure. ${ }^{[4]}$

Kniep et al. were able to reveal the radial inner structure of this seed crystal by a hexagonal cross section perpendicular to the seed axis, thus disproving the existence of a classical single crystal. ${ }^{[45]}$ It was concluded that the hexagonal seed crystal with single crystalline appearance and scattering behavior is a hierarchically ordered inorganic organic com posite superstructure with periodic orientation of hexagonal primary apatite nanocrystals, ${ }^{[49]}$ or, in our words, a mesocrys tal (see also Figure 1).

In a more recent study, the internal nature of the hexagonal seed crystals (Figure 7, left) was investigated in more detail. ${ }^{[50]}$ Figure 7 (right) shows the growth model for the observed radial outgrowth. It agrees with the mesocrystal scheme presented in Figure 1 but modified for the case of hexagonal building units. ${ }^{[50]}$ 

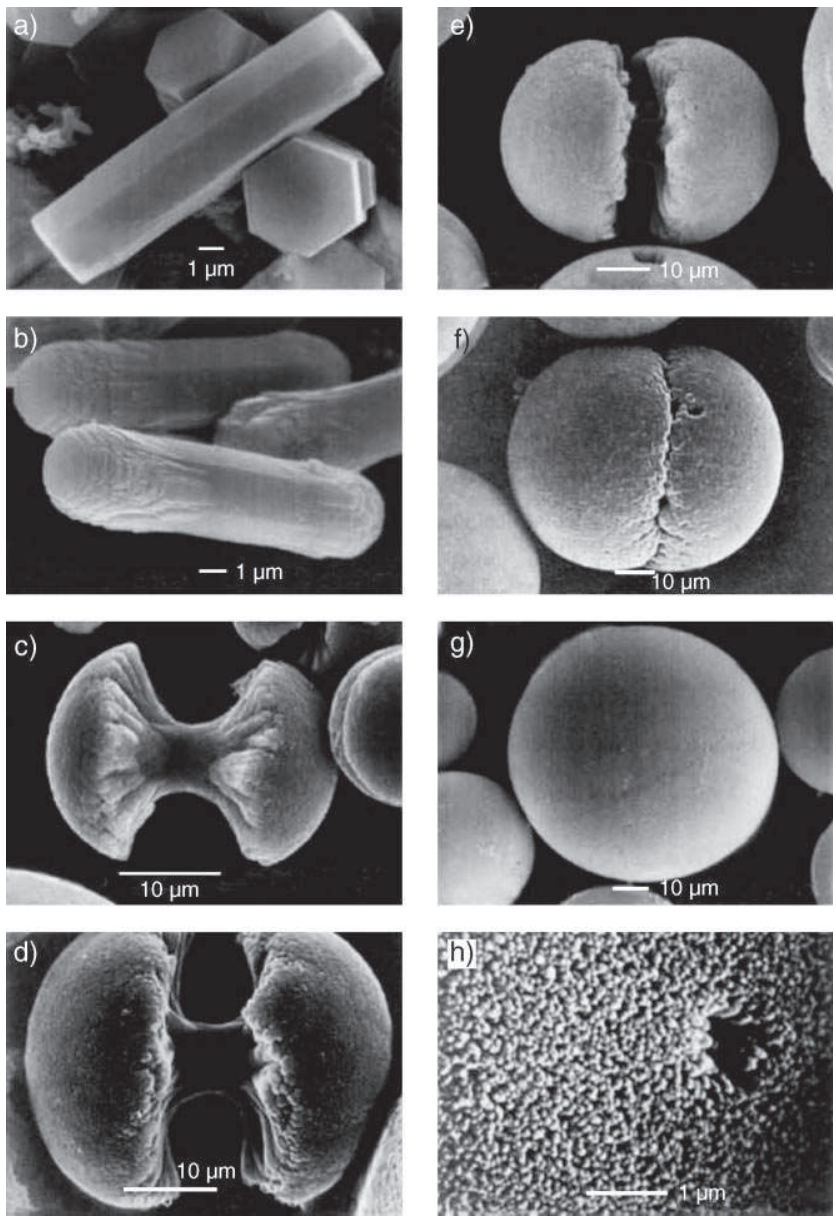

Figure 6. Selected sequence of SEM images of progressive stages of self assembled (hierarchical) growth of fluorapatite aggregates in a gel atin gel (morphogenesis): from an elongated hexagonal prismatic seed (a) through dumbbell shapes ( $c$ f) to spheres ( $g$ ); the surface of a just closed sphere also consists of needlelike units ( $h$ ) following the general principles of self similarity. Intrinsic electric fields were sug gested control factor for the rod dumbbell sphere fractal growth. Pic ture reproduced from ref. [45].

The hexagonal pattern, already known from $\mathrm{X}$ ray diffraction studies, ${ }^{[47,48]}$ was also found in high resolution micrographs with subsequent fast Fourier transform (FFT) analysis (Figure 8, top). Electronic filtering and enhancement of this image revealed structural defects, which were attrib uted to a collagen triple helix strand (white circle Figure 8, bottom) ${ }^{[50]}$ the memory of the former grain boundaries that are stabilized by organic material.

In addition, a superstructure periodicity of $10 \mathrm{~nm}$ was revealed, in good agreement with a tecton or primary nanoparticle size of about $10 \mathrm{~nm} \cdot{ }^{[50]}$ Furthermore, TEM of a focused ion beam milled sample showed pores and channels at the grain boundaries containing an amorphous phase, ${ }^{[51]}$ giving final evidence for the mesocrystalline nature of the well facetted hexagonal superstructure (see also Figure 1).

Reactions in gels appear to be well suited for the generation of mesocrystals as crystal growth in gels takes place under very high supersaturation ${ }^{[52]}$ leading to increased nucleation of small clusters the building units for the
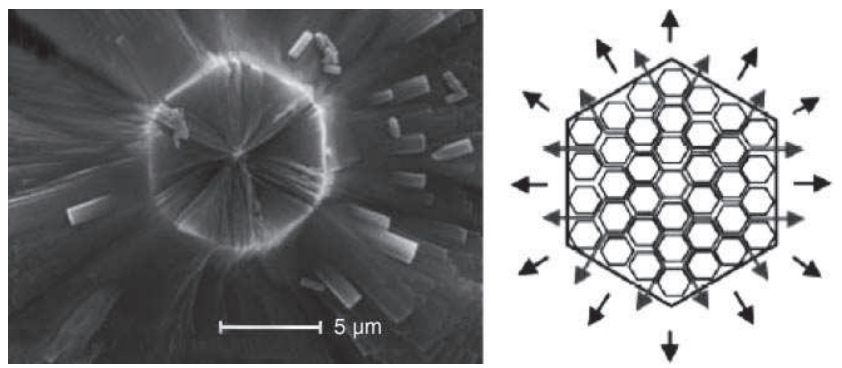

Figure 7. Left: SEM image of the fracture area of a central seed of a fractal composite aggregate. The fracture surface is dominated by a radial pattern. SEM (vacuum) was used instead of "environmental SEM" (freezing of sample) because areas of structural weakness are made visible more clearly by shrinking effects during evacuation (drying). Right: Idealized two dimensional arrangement of hexagonal nanoparticles forming a hexagonal nanoensemble (nanosuperstruc ture). The organic component inside and between the crystalline build ing units is omitted for clarity. The inner lines in the right Figure indi cate possible directions of preferred cleavage, the outer arrows show the radial structure of the cleavage. Reprinted from ref. [50] with per mission of the Royal Society of Chemistry.

mesocrystals. Simultaneously, convection or turbulence throughout crystallization can be suppressed, thus allowing the interaction potentials between the particles to dominate the mutual alignment of the particles. This process explains why many of the most defined mesocrystals are observed in gels.

Whereas gelatine gels can be considered to interact with inorganic crystals, at least through their charged groups, polyacrylamide gels can be considered to be essentially inert. The growth of $\mathrm{CaCO}_{3}$ in polyacrylamide gels led to remark able pseudo octahedral calcite mesocrystal morphologies built up of rhombohedral primary nanocrystallites (Figure 9). ${ }^{[53,54]}$ The external faces of the superstructure could even be indexed and a growth model based on hierarchical aggregation of rhombohedral subunits was pro posed. ${ }^{[33]}$ As already found for the fluorapatite hexagonal seeds, the crystallographic orientation of the subcrystallites is almost perfect, and the organic matrix appears to be interspaced between individual crystallites (Figure 9). ${ }^{[53]}$ However, whereas the fluoroapatite diffraction pattern was that of a single crystal, ${ }^{[47]}$ the calcite mesocrystals indicated a slight orientational distortion of the diffraction spots (Figure 9) corresponding to an average mosaic spread of $3.9 \pm 1.1$ degrees. This result nevertheless still confirms a high orientational order of the subunits in the mesocrystal. ${ }^{[53]} \mathrm{We}$ attribute this difference to the fact that the calcite system contains many vacancies and is potentially twinned (to allow construction of an octahedra from rhombohedra), whereas the particles from Kniep et al. have a higher symmetry and are clearly rather tightly packed.

Varying the polyacrylamide hydrogels by copolymeriza tion with charged acrylamidopropanesulfonate (AMPS) to give polyacrylamide co acrylamidopropanesulfonate (PAAm co PAMPS), the morphology of the calcite meso crystals could be tuned from the pseudo octahedral ${ }^{[53]}$ towards a cubooctahedral morphology with increasing 


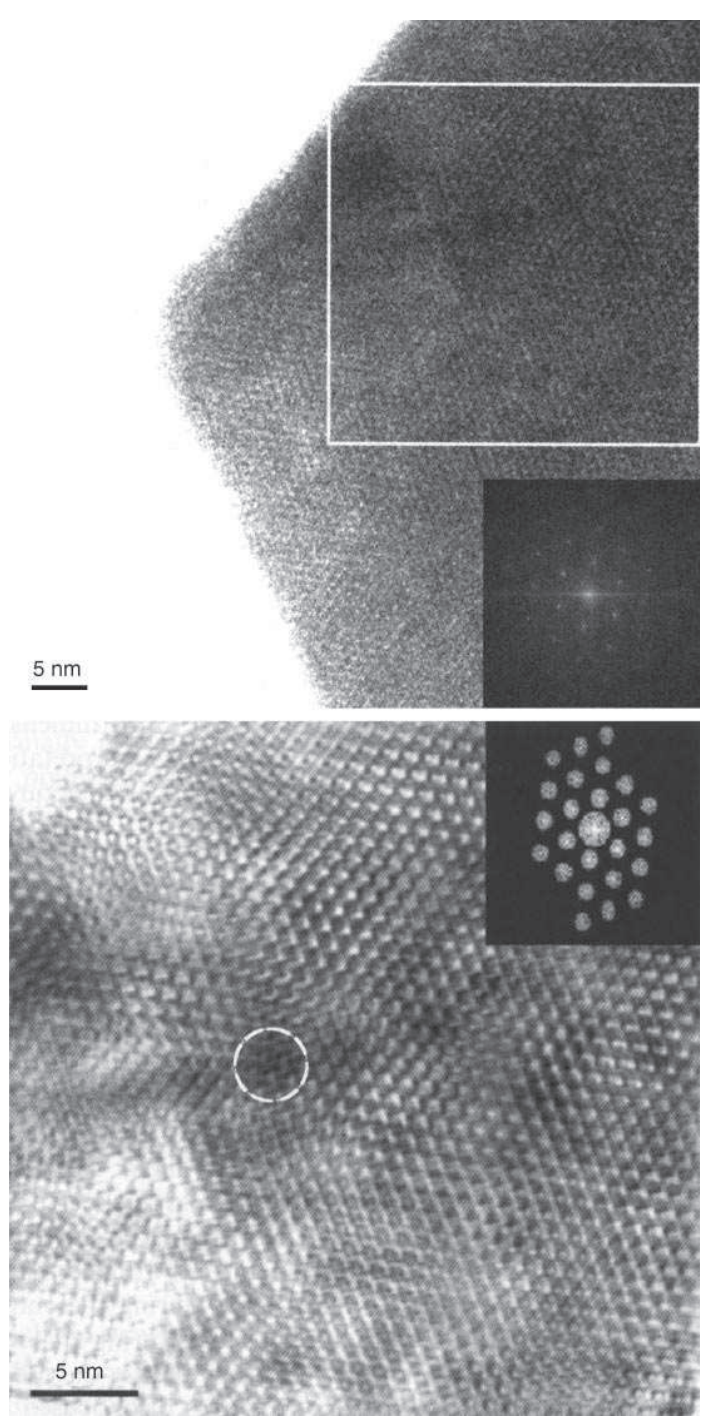

Figure 8. Top: High resolution electron micrograph of a composite seed (fast ion bombardment (FIB) preparation) viewed along [001]. The FFT (inset, bottom right) is characterized by hexagonal symmetry. Structural disorder of the composite (defects, mosaic structure) is indicated by diffuse reflections and by vanishing of higher order peaks. Bottom: Filtered and enhanced view of the white framed area of the top image. The overall hexagonal pattern is significantly broken inside the area of the white circle. The inset represents the mask used for the filter process (reflections observed). Reproduced from ref. [50] with permission of the Royal Society of Chemistry.

amounts of the charged AMPS in the copolymer gel (Figure 10) ${ }^{[55]}$ The substructure of the mesocrystals from aligned smaller crystals could be nicely visualized (Fig ure $10 \mathrm{c}, \mathrm{d})$.

One important conclusion of this study was that the alteration of the functional groups in the hydrogel changed not the mesocrystal formation as such, but the morphogenesis process, shedding some light onto the question why meso crystals exhibit defined outer faces and how they can be influenced. ${ }^{[55]}$

Mesocrystals can not only be formed in gel matrices with their special slow transport conditions, they can also form
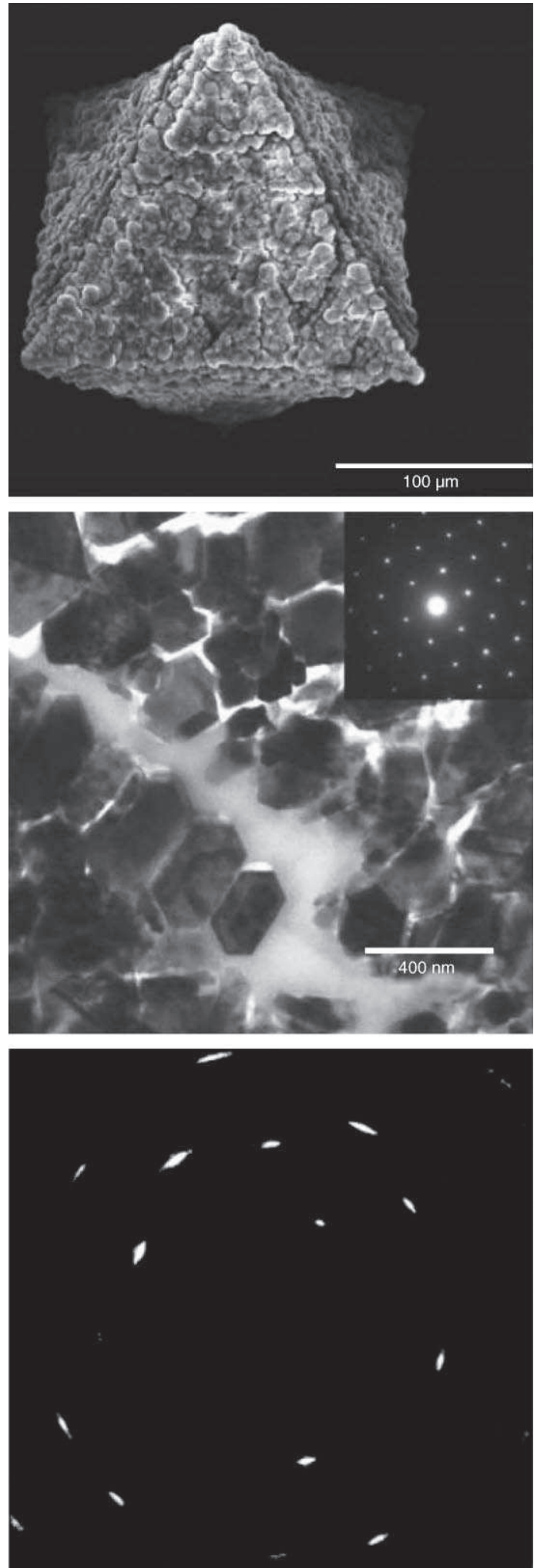

Figure 9. Top: SEM image of a calcite aggregate grown in a polyacryl amide gel with characteristic pseudooctahedral morphology. Middle: TEM image of the microstructure of one such aggregate grown in poly acrylamide and showing the alignment of individual crystallites. (inset: an electron diffraction pattern of an individual calcite crystal). bottom: Single crystal like diffraction pattern of the calcite aggregate. Reprinted from ref. [53] with permission of the American Mineralogical Society. 

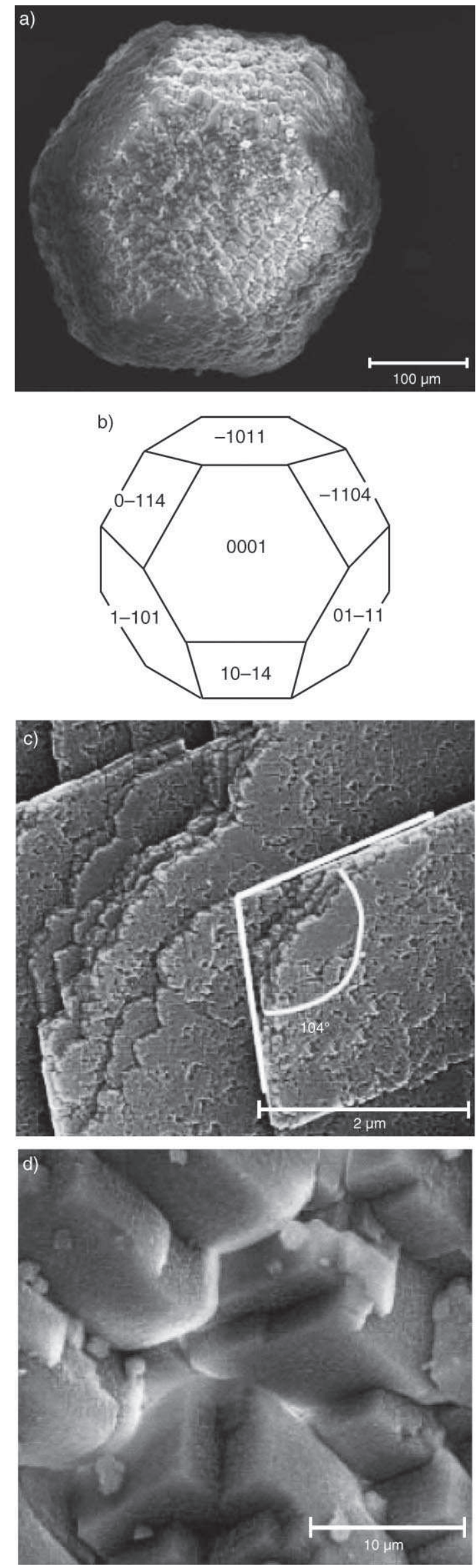

directly in solution. Among the first reported three dimen sional mesocrystals was a pseudocubic hematite $\left(\alpha \mathrm{Fe}_{2} \mathrm{O}_{3}\right)$ particle. ${ }^{[56}{ }^{59]}$ For this crystal, the typical but remarkable high orientational alignment of the nanoparticle subunits as well as the iso aligned nanoparticle building units was clear even from electron diffraction images (Figure 11) ${ }^{[59]}$ However the result were interpreted as being from single crystal particles with internal discontinuities. ${ }^{[59]}$ According to this interpreta tion, it was noted that the reported monodisperse polycrys talline hematite particles grow through a dissolution recrys tallization mechanism and not through an aggregation based mechanism, although a "characteristic internal structure" of the pseudocubic particles was suggested. Furthermore, it was noted that the adsorption of anions plays an important role for the morphology and internal structure control where $\mathrm{Cl}^{-}$ ions were suggested to remain in the mesocrystal interior. ${ }^{[59]}$ In our opinion, these nice results could also be explained by the controlled aggregation of primary nanoparticles and mesocrystal formation, analogous to the other cases. The experimental results however clearly reveal the nanocrystal line substructure as well as the radial alignment of elongated subcrystals (Figure 12) resulting in different crystal orienta tions according to their position.

Another example for mesocrystals formed directly from solution without any additive is $\left(\mathrm{NH}_{4}\right)_{3} \mathrm{PW}_{12} \mathrm{O}_{40}{ }^{[60}{ }^{64]}$ In these crystals, nanocrystals were unidirectionally aligned and epi taxially connected to form dodecahedral aggregates, and the analogy of the mesocrystal aggregate to a single crystal in terms of diffraction analysis was underlined. In addition, the mesocrystals were found to be porous. ${ }^{[62]}$ Comparison of the cesium and ammonium salts which precipitated at different temperatures allowed a variation of the degree of order in the mesocrystals. ${ }^{[65]}$ The solubility of the salts was considered to be responsible for the control of the microstructure morphol ogy with the higher solubility favoring the regular polyhedral shape. ${ }^{[65]}$ This result is qualitatively in agreement with the finding that the mesocrystal morphogenesis in gels is influ enced by the functional groups of the gel, which in turn determines the gel crystal surface interaction and therefore the surface conditions of the mesocrystal.

Mesocrystal formation was also observed for Zeolites. ${ }^{[6,67]}$ In these experiments, the zeolite first forms "nanoslabs" containing 2, 6, 12, or 48 zeolithic unit cells, which then vectorially align to larger structures. TEM however clearly revealed that those bigger units are composed of the smaller building blocks, with all the textures and defects typical for mesocrystals.

A very detailed study on mesocrystal formation directly in solution and subsequent fusion to iso oriented crystals was reported for copper oxalate. ${ }^{[68,69]}$ In this case, nanoparticles

Figure 10. Pseudocubooactaedral calcite mesocrytals grown in a PAAm co PAMPS hydrogel containing $10 \mathrm{~mol} \%$ of monomers bearing sulfonate groups. a) SEM micrograph, b) schematic illustration of the pseudocubooctaedral morphology, c) flattened vertices of pseudo cubooctahedral particles showing calcite rhombohedra faces, d) orien tation of rhombohedral subcrystals on aggregate faces. Images (c) and (d) clearly show the substructure of the mesocrystal. Figure repro duced from ref. [55]. 

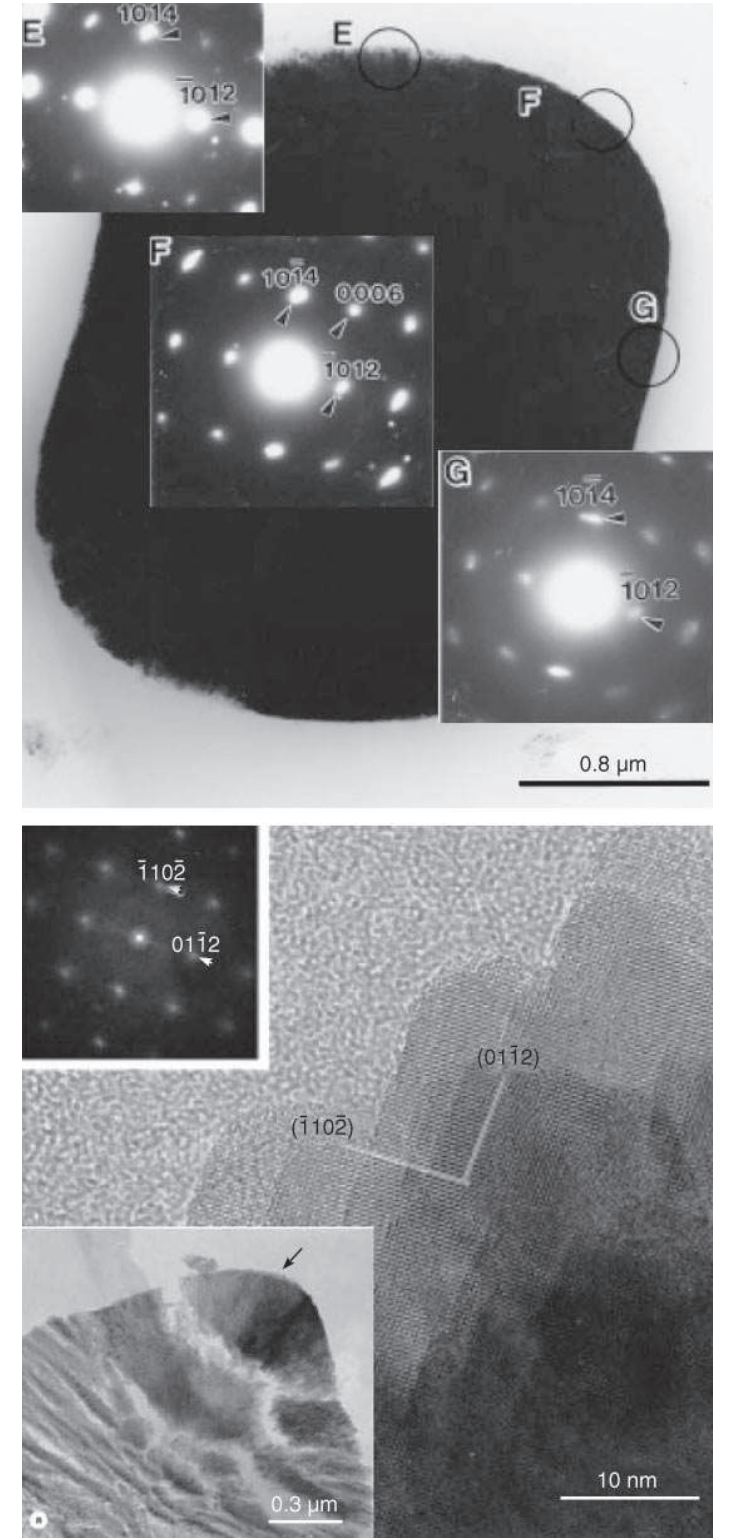

Figure 11. Hematite $\left(\alpha \mathrm{Fe}_{2} \mathrm{O}_{3}\right)$ mesocrystals: top: Transmission elec tron micrograph of a thin section and electron diffraction patterns obtained from the parts E, F, and G. Bottom: inset lower left is the transmission electron micrograph of a section around a corner of a pseudocubic particle; main photo: High resolution electron micro graph of the area indicated by an arrow in the lower left inset. Upper left inset is the Fourier diffractogram of the lower inset. Figure repro duced from ref. [59] with permission of Academic Press.

were found to arrange almost perfectly to a mesocrystal, which could be influenced in terms of morphology by hydroxymethylpropylcellulose (HPMC, Figure 13). It was found that the polymer influences nucleation, nanocrystal growth, and aggregation by selective interaction of the polymer with the more hydrophobic lateral (110)/(1111) $\varepsilon$ faces of an [001] elongated nanocrystal as compared to the hydrophilic (001) $\alpha$ face. ${ }^{[69]}$

Increasing polymer concentration led to the formation of more but smaller crystal nuclei as a result of the decrease of
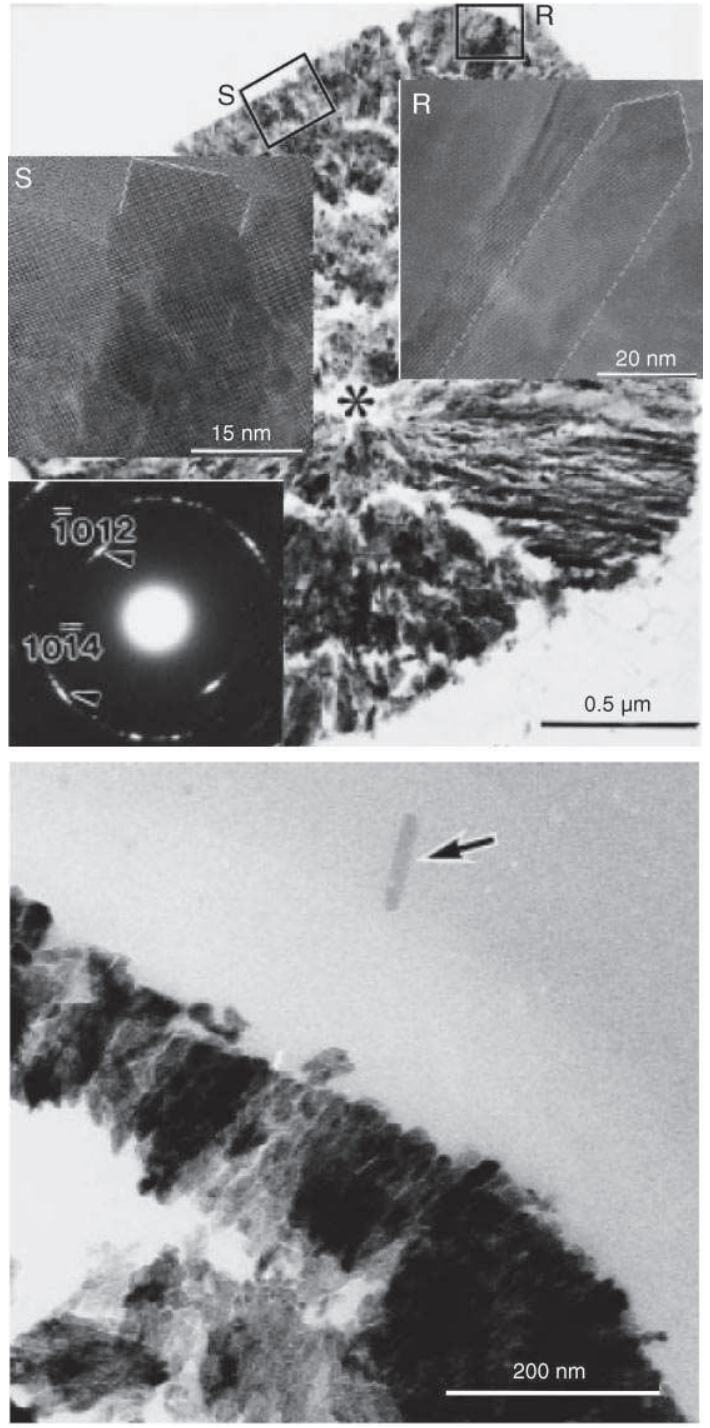

Figure 12. Hematite $\left(\alpha \mathrm{Fe}_{2} \mathrm{O}_{3}\right)$ mesocrystals: top: Transmission elec tron micrograph of a thin section together with HRTEM pictures of areas $\mathrm{S}$ and $\mathrm{R}$ as insets. The $*$ notes the position where the electron diffraction data (shown in the lower inset) was taken. Bottom: TEM micrograph of a thin section of a pseudocubic particle. An arrow indi cates a subcrystal separated from the solution. Figure reproduced from ref. ${ }^{[59]}$ with permission of Academic Press.

the interfacial tension between nuclei and solution. The specific HPMC adsorption to the lateral $\varepsilon$ surfaces of the growing nanocrystals, once a sufficient HPMC concentration was reached, led to the formation of anisotropic shapes. Upon aggregation of these nanocrystals, a mesocrystal is formed as intermediate but is apparently not stable because of the low repulsive electrostatic and steric forces. Depletion floccula tion of the weakly adsorbed polymer layers was suggested to be the reason for the depletion of the polymer from the inner mesocrystal surfaces to the outer mesocrystal faces resulting in attraction of the nanoparticles with subsequent nano particle fusion to give an iso oriented crystal. ${ }^{[69]}$ Nevertheless, this iso oriented crystal was shown to be not single crystalline, as line width analysis in wide angle $\mathrm{X}$ ray scattering (WAXS) 
a)

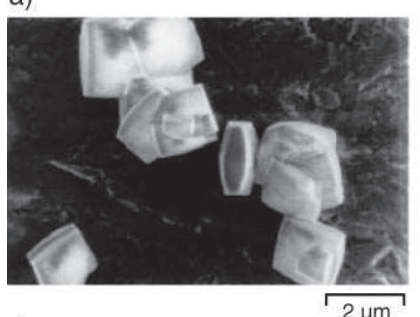

c)

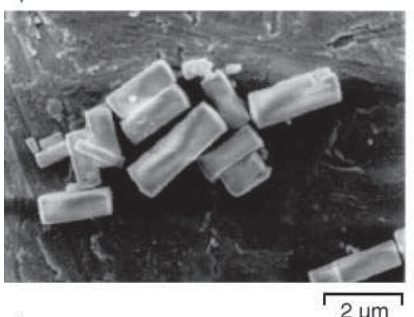

e)

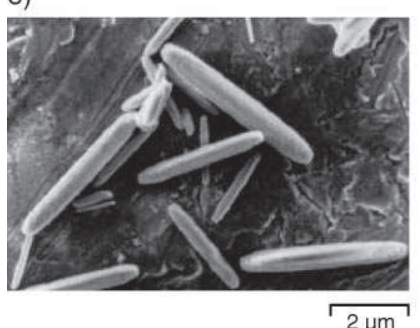

)
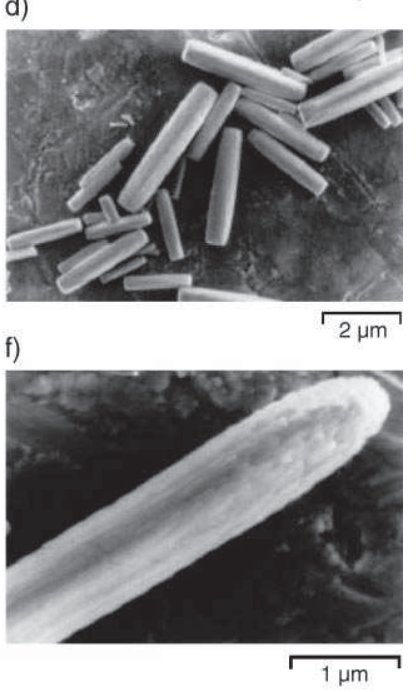

Figure 13. SEM micrographs of copper oxalate powders prepared a) without HPMC, b) with $0.005 \mathrm{gL}^{1} \mathrm{HPMC}$, c) $0.0195 \mathrm{gL}^{1} \mathrm{HPMC}$, d) $0.156 \mathrm{gL}^{1} \mathrm{HPMC}$, e) $0.625 \mathrm{gL}^{1} \mathrm{HPMC}$, and f) a higher magnifica tion of (e) showing the mesocrystal structure. Figure reproduced from ref. [69] with permission of Academic Press.

reveals the nanometer size of the primary building units, which get smaller with increasing HPMC concentration. As typical for mesocrystals, electron diffraction indicated a minor, but detectable orientational disorder, in this case along the [001] direction, which also supports the nano particle aggregation based mechanism of mesocrystal forma tion (Figure 14).

The whole mesocrystal formation process originally proposed is illustrated in Figure 15. In this case, the role of the polymeric additive on nucleation, growth, and organized aggregation to a mesocrystal is shown, and a coding of the mesocrystal morphology by tuning the surface energies of the nanocrystal building units and thus the nanocrystal morphol ogy is suggested (that is, the morphology of the nanocrystal is a major influence on the shape of the resulting mesocrystal). In this particular case, the mesocrystal appears to adopt the same morphology as the nanoparticles. It is remarkable to note that the copper oxalate mesocrystals retain their morphology and nanometric substructure throughout decom position into copper oxide. ${ }^{[70]}$

In a later and more detailed study on the copper oxalate system, ${ }^{[71,72]}$ the "brick by brick" aggregation mechanism could be revealed in a time dependent study. ${ }^{[71]}$ However, the mesocrystal core parallel to the [110] direction showed poor organization with increasing order towards the particle surface and with increasing nanoparticle size. The particle
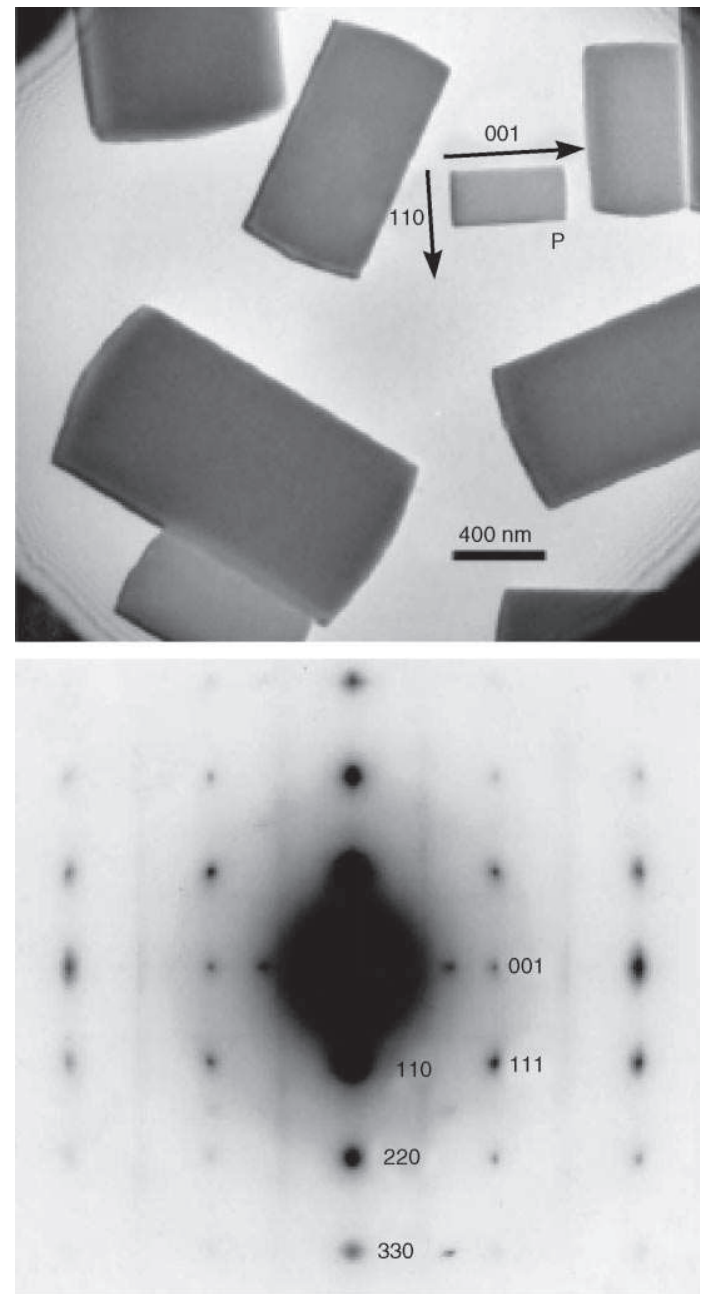

Figure 14. Top: TEM micrograph of copper oxalate with a square rod shape, precipitated in presence of $0.0195 \mathrm{gL}^{1} \mathrm{HPMC}$ (Figure 13 c) and bottom: electron diffraction pattern of the smallest particle on the micrograph, zone axis [110]. Figure reproduced from ref. [69] with per mission of Academic Press.

density was higher at the hydrophobic $\varepsilon$ surfaces than the hydrophilic $\alpha$ surface. Kinetic studies revealed a fast nucle ation, growth, and agglomeration onset of primary mesocrys tals leading to the relatively unordered particle core. This step is followed by a much slower growth stage with controlled aggregation as the predominant growth mechanism, which amplifies the mesocrystal morphology. Secondary particle nucleation was found as a competing event. Upon extended ripening, likely by dissolution recrystallization, high energy surfaces were eliminated. ${ }^{[71]}$ This study implies that a meso crystal is more a kinetic, metastable intermediate than a thermodynamically stable product.

The studies were extended onto the related cobalt oxalate dihydrate. ${ }^{[73]}$ As was found for copper oxalate, WAXS showed the crystals were composed from nanometer building units. Atomic force microscopy (AFM) revealed strings of nano domains oriented along the principal axis of the particle (Figure 16) and that the lateral and basal faces of the precipitate are composed of stacked nanoparticle layers with a thickness between $57 \mathrm{~nm}$. 


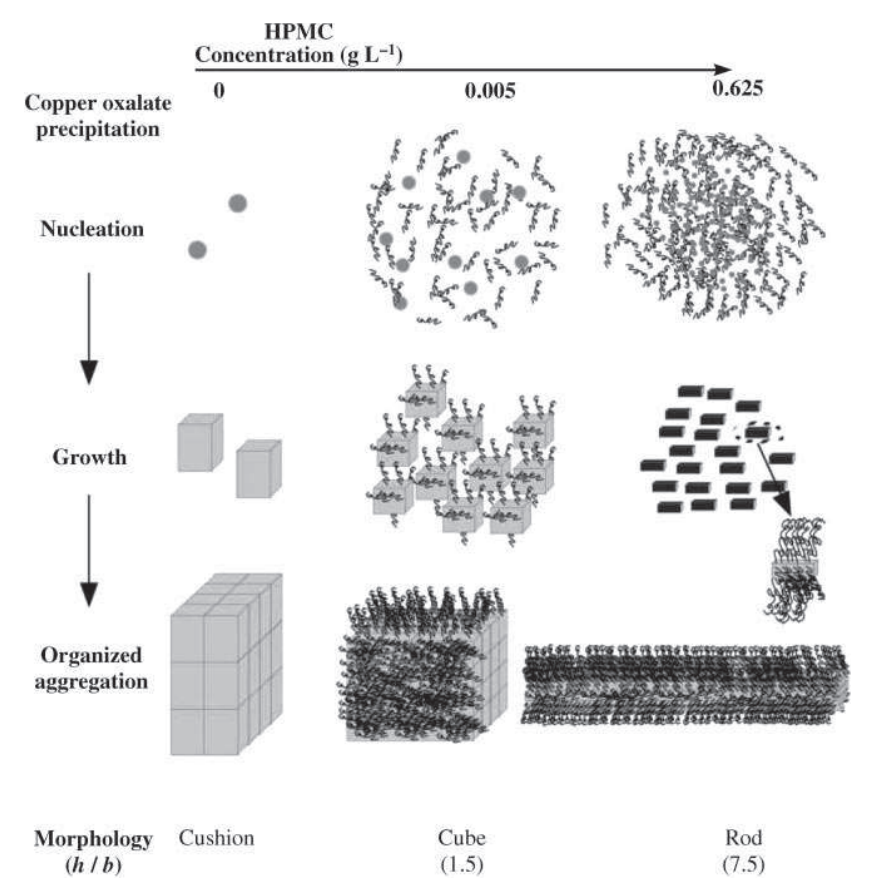

Figure 15. Schematic representation copper oxalate precipitation show ing the influence of HPMC on the three major steps of particle forma tion (h height, b breadth). Figure reproduced from ref. [69] with permission of Academic Press.

A time resolved HRSEM study revealed the formation mechanism of the mesocrystal (Figure 16). ${ }^{[73]}$ Poorly crystal line primary particles $(10 \mathrm{~nm})$ first aggregate to form secondary particles $(23 \mathrm{~nm})$. The latter subsequently aggre gate to form polydisperse elongated particles (Figure 16, middle). These elongated particles also aggregate at the end and center of a growing particle (Figure 16, bottom) building the mesocrystal. Afterwards, there is a layer by layer growth by aggregation of primary particles onto the lateral external faces. Thus the mesocrystal is a core shell particle or core shell mesocrystal, where the core is quite disordered owing to the polydispersity of the nanoparticle building units. ${ }^{[73]}$ The presence of steps and kinks on the external faces is reminiscent of classical crystallization models except that the atoms or molecules are replaced by nanoparticles. The changes in supersaturation and thus ionic strength, which is closely associated to colloidal stability of nanoparticles, were suggested to play a major role in the process of ordering the nanocrystals into a mesocrystal because the ordered meso crystal shells were formed at a lower supersaturation than the disordered cores. However, the ordering of nanoparticles to a mesocrystal can certainly not be reduced to the nanoparticle colloidal stability issue alone. An example are $\mathrm{CaCO}_{3}$ mesocrystals, which are formed by the selective adsorption of poly(styrene sulfonate) PSS onto the highly polar calcite (001) nanoparticle faces. ${ }^{[74]}$ If the nanocrystal is considered as a dielectric, adsorption of PSS onto one (001) face results in repulsion of negative ions from the opposite (001) face so that a dipole field is built up. It was argued that this situation can lead to a controlled arrangement of the nanoparticle subunits to give mesocrystals (Figure 17). These mesocrystals are
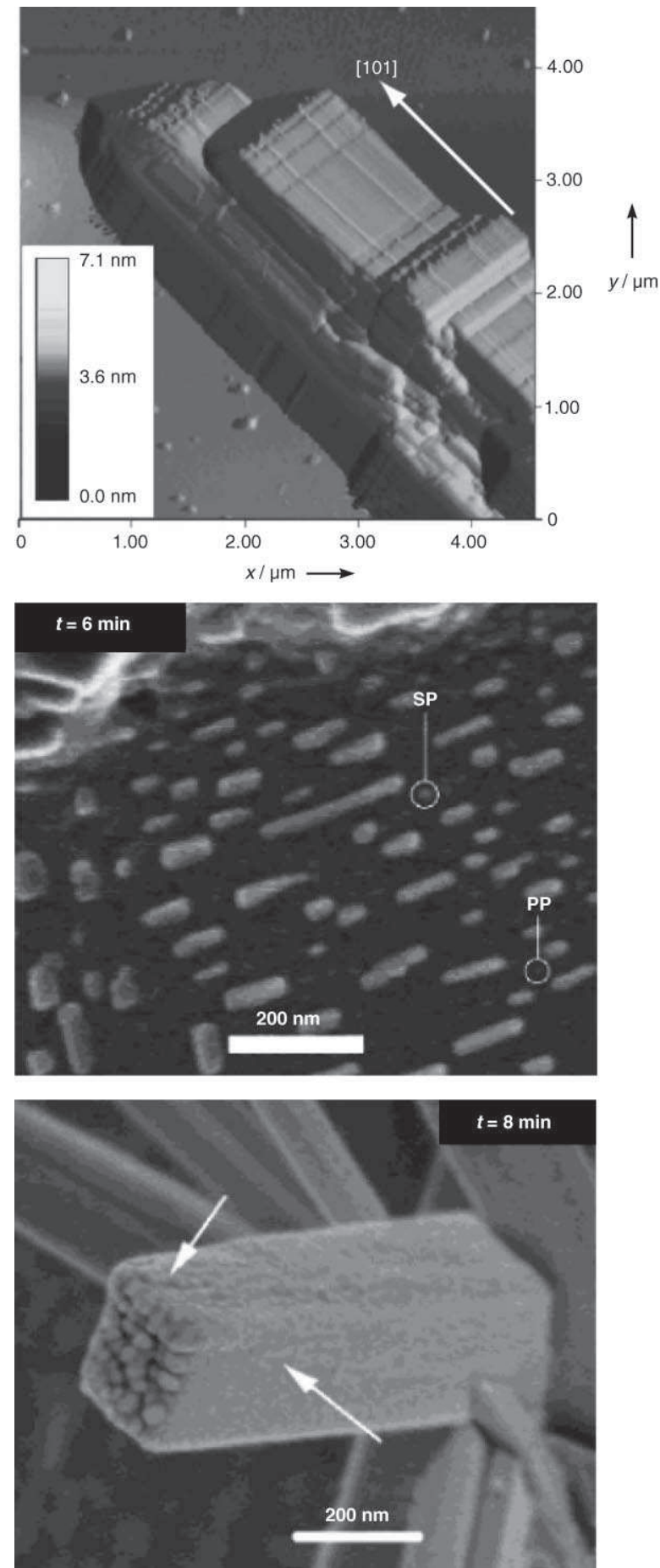

Figure 16. Top: AFM image of a $\mathrm{CoC}_{2} \mathrm{O}_{4} \cdot 2 \mathrm{H}_{2} \mathrm{O}$ particle aged $1 \mathrm{~h}$ in sus pension. Middle: Low voltage high resolution (LVHR) scanning elec tron micrograph of uncoated cobalt oxide dihydrate primary (PP) and secondary (SP) particles after 4 min reaction time. Bottom: LVHRSEM micrograph of cobalt oxide dihydrate mesocrystal formed from secon dary particle aggregates. The arrow pointing towards the end of the growing particle shows the agglomeration of polydisperse nanoparti cles of $23 \mathrm{~nm}$ size, whereas the other arrow pointing at the lateral external faces indicated the layer by layer growth on these faces. Figure reproduced from ref. [73] with permission of the American Chemical Society. 

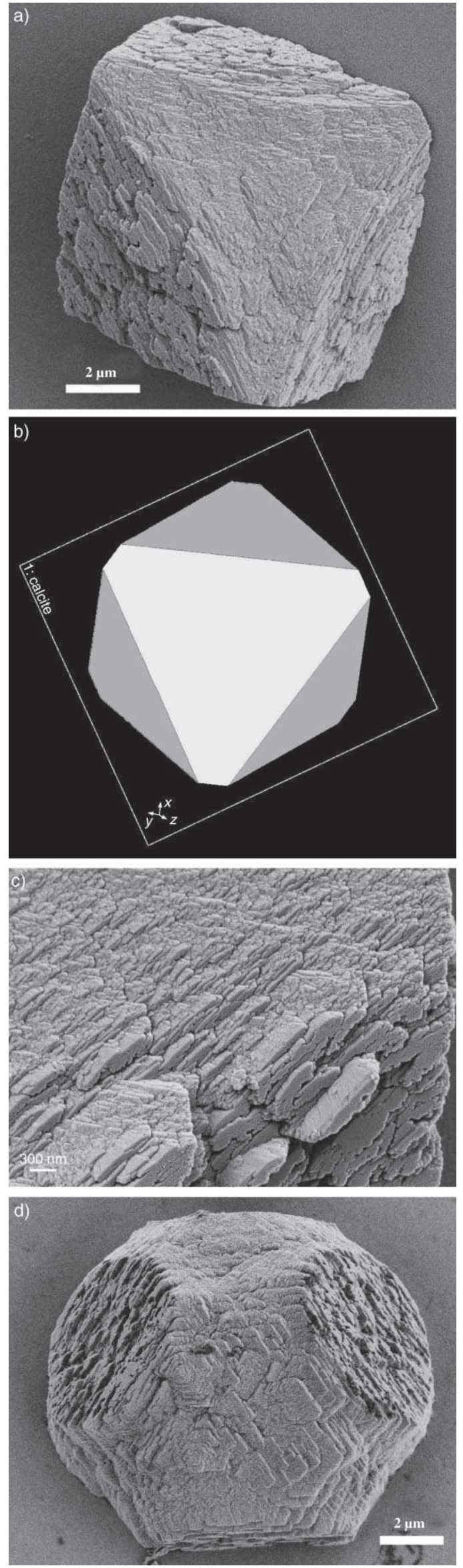

highly porous but show their common mutual high orientation by a rather perfect tensorial birefringence under crossed polarizers. Note that calcite is highly birefringent except when observed from the [001] direction (white plane in the Cerius model, Figure 17).

Variation of the $\mathrm{CaCO}_{3} / \mathrm{PSS}$ ratio resulted in very system atic variations of the mesocrystal morphology, including a whole family of highly defined rounded structures (for one case with six elliptic faces, see Figure 17). Higher PSS concentrations lead to increasing exposition of the highly polar (001) face, finally resulting in a multicurved convex concave structure with broken symmetry along the [001] direction at high $\mathrm{Ca}^{2+}$ and PSS concentrations. This result shows the importance of dipole fields as ordering forces for mesocrystal formation. ${ }^{[74]}$

Interestingly, there is evidence that some biominerals are also mesocrystals. For example, sea urchin calcite skeletal elements scatter like single crystals but have a nearly isotropic fracture behavior, which is untypical for single crystalline calcite. Indeed, in a very recent study, an AFM investigation of a fracture pattern of sea urchin skeletal elements revealed a rough, clusterlike pattern without any preferred plane orientation. ${ }^{[75]}$ The detected subunit size was in the range of $3050 \mathrm{~nm}$. In the same study, a synthetic calcite mesocrystal was reported, which was grown from an amorphous precursor in presence of polyaspartic acid. This calcite crystal consisted of uniformly shaped, oriented, and interlocked planar trian gular growth domains with a length of $80150 \mathrm{~nm}$, width 40 $100 \mathrm{~nm}$, and a thickness of $36 \mathrm{~nm}$.

Mesocrystals can not only be obtained for inorganic but also for organic crystals. An advantage of using organic nanocrystals is that these are molecular crystals, where a dipole moment as well as an anisotropic polarizability can be encoded in the molecule. Such mesocrystals are particularly well suited to learn about the mechanism of mesocrystal formation. For example, alanin is dipolar, and thus meso crystals can be formed using a block copolymer additive that has an anionic polyelectrolyte block which selectively adsorbs onto the positive (001) face of DL alanine. This process creates platelets with a dipole moment along the $c$ axis (Figure 18). ${ }^{[30]}$ The dipole moment along the [001] axis leads to the observed stacking of the nanocrystal platelets forming the mesocrystal where the individual building units are interspaced by the adsorbed polymer on (001).

A model example for a mesocrystal formed by anisotropic van der Waals attraction was reported by Taden et al. for dyes with an anisotropic polarizability. ${ }^{[76]}$ Amorphous particle precursors were made in a size controlled fashion by cooling the liquid nanodroplets of a miniemulsion. Spontaneous

Figure 17. $\mathrm{CaCO}_{3}$ mesocrystals formed in presence of PSS $\left(\mathrm{Ca}^{2+} 2.5 \mathrm{~mm}\right.$, PSS $\left.1 \mathrm{gL}^{\mathrm{l}}\right)$ a) SEM micrograph of a single meso crystal. b) Cerius ${ }^{2}$ calculated morphology of a $\mathrm{CaCO}_{3}$ single crystal with the mesocrystal morphology (gray (104), white (001)). c) higher magnification clearly indicating the alignment of primary particles and the porous nature of the mesocrystal. d) lowering the PSS concentra tion ( $\mathrm{Ca}^{2+} \quad 2.5 \mathrm{~mm}$, PSS $\left.0.5 \mathrm{gL}^{\mathrm{l}}\right)$ results in a curving of the $(001)$ planes. The former (104) planes are now six ellipses, illustrating that mesocrystals can easily exhibit highly defined curved morphologies. 

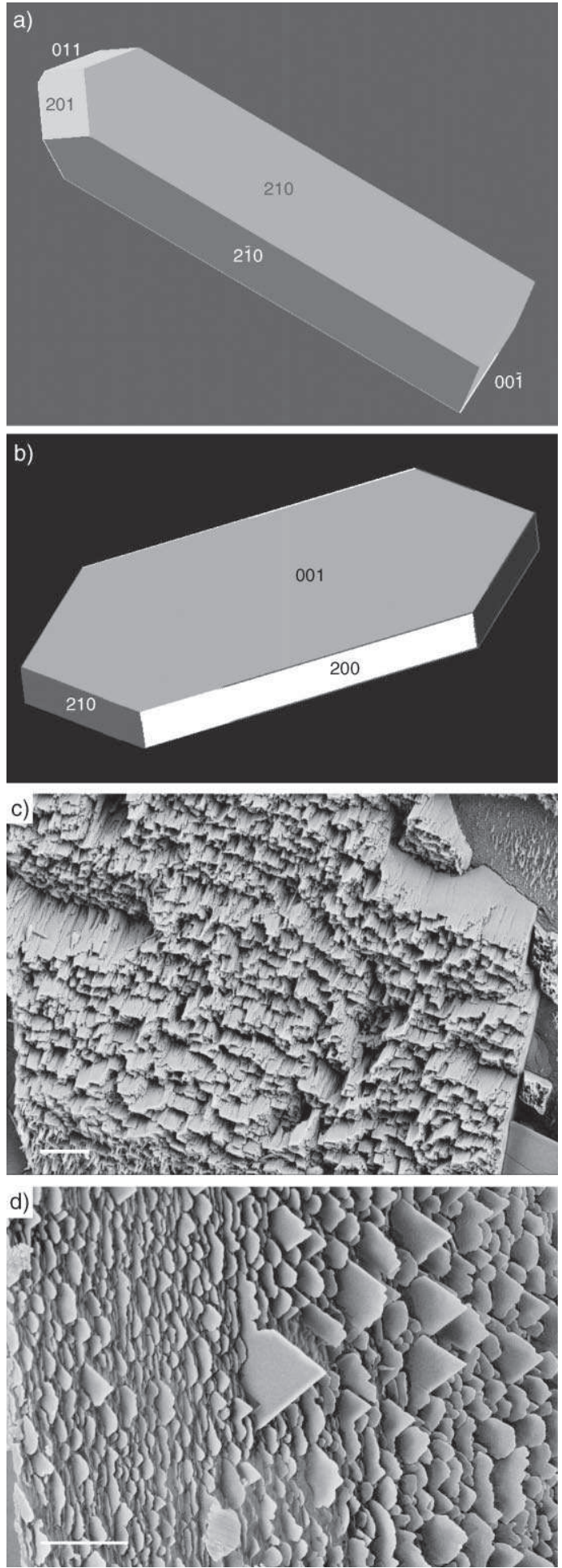

Figure 18. DL alanine crystals through crystallization of $10 \mathrm{~mL}$ of a supersaturated solution (from $65^{\circ} \mathrm{C}$ to $20^{\circ} \mathrm{C}$ ) a) default experiment without additive. b) Suggested mesocrystal subunit by addition of $1.0 \mathrm{wt} \%$ anionic blockcopolymer and selective adsorption onto (001). c) High resolution SEM of DL alanine crystals through crystallization by addition of $1.0 \mathrm{wt} \%$ block copolymer (scale bar $2 \mu \mathrm{m}$ ). d) Different cut of the same structure revealing the high orientational order of the nanocrystalline platelets (scale bar $3 \mu \mathrm{m}$ ). Figure reproduced from ref. [30]. rearrangement of many nanodroplets towards well defined linear mesocrystal aggregates was observed, which was accompanied by significant color changes of the dye super structures. These rodike particles could be ripened to larger three dimensional mesocrystals that retained the almost perfect molecular orientation found in the nanoparticle aggregate. This orientation could be demonstrated on turning the ripened mesocrystals under crossed polarizers (Figure 19, bottom).

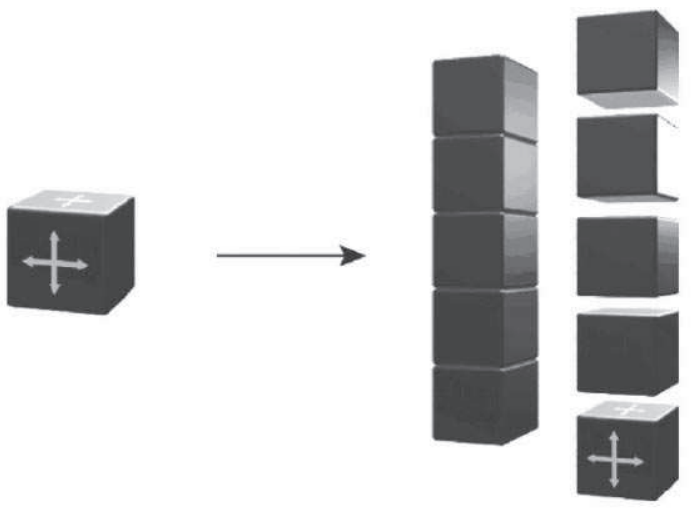

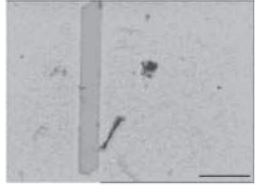

$0^{\circ}$

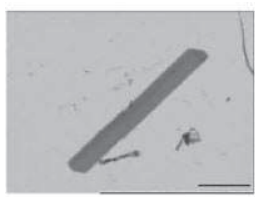

$45^{\circ}$

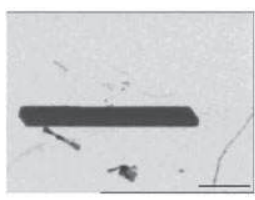

$90^{\circ}$

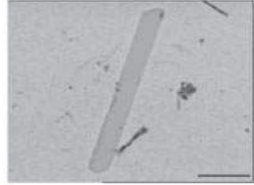

$15^{\circ}$

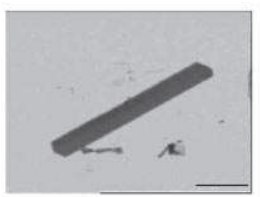

$60^{\circ}$

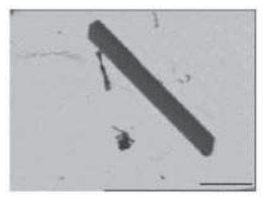

$135^{\circ}$

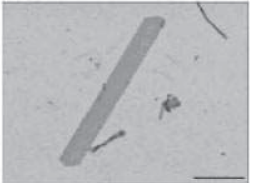

$30^{\circ}$
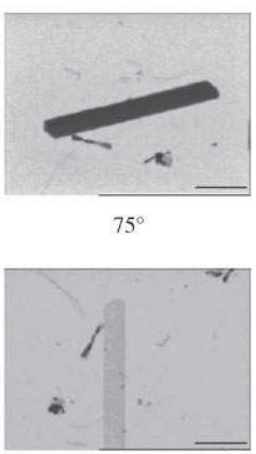

$180^{\circ}$
Figure 19. Top: Scheme to illustrate the directed mesoscale aggrega tion of dye nanoparticles. Because of the symmetry of the unit cell the primary nanocrystals formed show different polarizabilities along dif ferent planes. As is typical for van der Waals forces, similar polarizabili ties attract each other optimally ("attraction of the same"). In this rep resentation the light faces with the highest polarizability give the stron gest van der Waals force. As a result, aggregation and mesocrystal for mation occurs only in this direction. Bottom: series of polarization tilts of a selected large crystal of oil blue (scale bar $20 \mathrm{~mm}$ ). Figure reproduced from ref. [76] with permission of the American Chemical Society.

The fact that the dipole moment of such dyes is along the molecular axis and coupled to the maximum color allows the difference between polarizability and dipole moment as the driving force for organization to be studied. A high polar izability will lead to a high van der Waals attraction (light 
faces in Figure 19, top), a dipole moment will lead to an attraction of different dipoles. As the dye molecules are perfectly aligned perpendicular to the main axis of the mesocrystal, these experiments revealed tensorial differences in the polarizability of various nanocrystal faces to be the driving force for the formation of mesocrystals with the observed high orientational order. Whether or not the nanocrystalline building units in the mesocrystals fused together by oriented attachment ${ }^{[33]}$ to form a single crystal was not revealed.

In addition to the above examples, where mesocrystals are sufficiently long lived to be isolated at least as kinetically stable intermediates, there are also examples where meso crystals can only be postulated as short lived intermediates by indirect evidence in a "classical crystallization" event, ${ }^{[77]}$ which is usually expected to occur by molecule or ion by ion attachment.

In most cases, however, the speed of crystallization events makes the classical molecule or ion mediated crystallization picture unrealistic. For example, Rieger et al. have demon strated that the particle formation from highly supersaturated boehmite solutions is determined by the mixing process, which is orders of magnitude too fast to be covered by classical nucleation and growth theories. ${ }^{[78]}$ Even in the crystallization process of a mineral such as $\mathrm{BaSO}_{4}$, which has been intensively studied in the past and which was assumed as a model case for ion mediated crystallization, strong experimental evidence was found that crystallization also progresses by organized mesoscale aggregation and alignment. Judat and Kind analyzed the additive free crys tallization of $\mathrm{BaSO}_{4}$ for various supersaturation conditions ${ }^{[77]}$ and found clear evidence for a nanoparticle mediated crys tallization mechanism contradicting the classical ion medi ated mechanism. Electron microscopy and diffraction revealed a polycrystalline, but almost perfectly oriented mesocrystalline superstructure of primary $\mathrm{BaSO}_{4}$ nanocrystal subunits with the typical slight orientational distortions of the superstructure (data not shown; similar to Figure 8, right). It was proposed that a mesocrystal formed as an intermediate on the way to a porous $\mathrm{BaSO}_{4}$ crystal and various evidence for the absence of the classical crystallization pathway for this example was collected. ${ }^{[77]}$ However, in other regions of supersaturation, crystallization according to the classical mechanism was also observed.

These examples indicate that the evidence for mesoscale aggregation and organization towards mesocrystals should increase dramatically in the next few years as mesocrystals also appear to be regular intermediates in ordinary crystal lization reactions, which to date were assumed to be ion mediated. Typical areas in the parameter space to expect mesocrystals are high supersaturation ratios or corresponding low solubilities or ion products.

\section{Conclusions}

In summary, mesocrystals are oriented superstructures of nanocrystals with common outer faces, and are a new type of colloidal crystals formed from nonspherical, crystalline build ing units. Both the formation as well as the morphogenesis of mesocrystals apparently contradict the classical textbook knowledge on crystallization, where growth of shapes is based on the integration of atomic or molecular building blocks into energetically favorable sites on a growing crystal face. ${ }^{[79,80]}$ The adsorption of ions or molecules onto the crystal face is followed by subsequent diffusion across the surface to steps and kink sites ${ }^{[81]}$ which leads to a plane by plane growth of a single crystal. The relevant parameters for classical crystallization are molecular solubility (defining the speed of crystallization) and crystal face specific interface tensions (defining growth rates, relative exposure, and therefore the morphology of the crystal).

This type of crystallization is clearly not observed for mesocrystals, which are built from nanoparticle building units, where speed of crystallization and morphology of the super structure are only encoded in colloidal stabilization and vectorial long ranged interaction potentials. This principle delivers new tools and possibilities into the hands of chemists, as it is now possible to generate crystalline nano and mesostructures in a much broader and potentially useful way. The universal applicability of the classical crystallization picture was already questioned for a few years, ${ }^{[82]}$ partly as a result of the careful observation of biominerals.

In addition, mesocrystal formation processes may even be a common crystallization pathway in the formation of single crystals, especially in systems with very low molecular solubilities or high supersaturations. As a result of the progress in instrumentation, direct evidence for such meso crystals was recently discovered, which appear to be valid over a wide parameter space. The reason for the remarkable, almost perfect order of the nanocrystalline subunits which results in diffraction patterns similar to single crystals is still unknown, but tensorial polarization forces and dipole fields are discussed. ${ }^{[45,74]}$ Indeed, theoretical studies suggest that a nonspherical charged object in an electrolyte creates a screened electrostatic potential that is anisotropic at any distance ${ }^{[83]}$ so that mutual ordering can be induced.

There are however some criteria by which the presence of a mesocrystal either as an intermediate or as the final product can be identified. Even if the nanoparticle orientational order is almost perfect, the porosity in mesocrystals can be quite high as a result of nanoparticle polydispersity and stacking defects during mesocrystal formation. These defects are transformed into pores with organic or foreign ion inclusions upon ripening to a single connected crystal. ${ }^{[77]}$ Organized grain defects or amorphous interlayers can occur in the same way.

The reasons for the formation of the external mesocrystal faces are still unknown. In the most simple case, they maybe simply the reflection of the nanocrystal morphology ${ }^{[69]}$ but in the majority of cases, mesocrystals exhibit external morphol ogies not related to the primary crystal symmetry, sometimes they have the typical rough faces, but a higher symmetry than the primary units, sometimes they even have curved, para bolic, or elliptic faces, as shown in Section 4.

In an extreme case, a mesocrystal can, although vecto rially quite perfectly aligned, completely loose any macro scopic crystalline appearance and can exhibit morphologies 


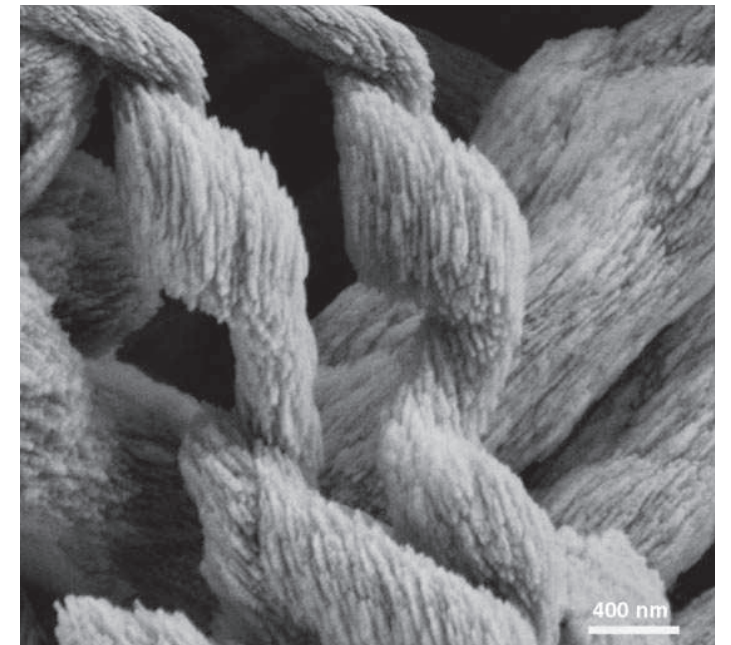

Figure 20. SEM image of helical $\mathrm{BaCO}_{3}$ fibers formed in presence of a stiff phosphonated block copolymer. Reproduced from ref. [84] with permission of Nature Publishing Group.

like the $\mathrm{BaCO}_{3}$ helices shown in Figure 20, which were formed after selective encoding of special faces of the orthorhombic primary nanoparticle building units by additive adsorption. ${ }^{[84]}$ Not only the high alignment of elongated nanoparticles in these helices is remarkable, also the apparent "communication" between the two helices is. Identical morphologies and irregular helix pitch strongly indicate the presence of ordering electric fields in addition to the constraints exerted by the face selective polymer adsorption. Helices from twisted twin subunits were also reported for triclinic $\mathrm{K}_{2} \mathrm{Cr}_{2} \mathrm{O}_{7}$ and $\mathrm{H}_{3} \mathrm{BO}_{3}$, formed in a diffusion field created around a growing crystal in poly(acrylic acid) or poly(vinyl alcohol) gels ${ }^{[85]}$ or orthorhombic $\mathrm{K}_{2} \mathrm{SO}_{4}$ in a viscous poly(acrylic acid) solution (PAA) ${ }^{[86]}$ In the latter case, the crystal habit was modified by selective PAA adsorption leading to tilted platelike crystals. This effect is in addition to the diffusion limited growth condition, which controls the assembly of the tilted subunits. Even the direction of the helical turn could be influenced for $\mathrm{K}_{2} \mathrm{Cr}_{2} \mathrm{O}_{7}$ in a gel medium by molecular recognition of the enantiomeric triclinic subunit surfaces by glutamic acid enantiomers. ${ }^{[87]}$

Nanoparticle surface interactions appear to be of impor tance for the formation of a mesocrystal and possibly are also responsible for the formation of external faces, which can be indexed like those of a single crystal. Mesocrystals are a new type of nanostructured matter with potentially exciting applications, either in construction materials (as exploited by nature for biominerals) or as functional ceramics (e.g. with color or magnetic properties). However, there is still much to be learned about the forces guiding mesocrystal assembly and the exact formation mechanisms.

We thank the Max Planck Society for financial support. Dr. Tong Xin Wang is acknowledged for the material in Figure 17 and the frontispiece.
[1] M. Antonietti, G. Ozin, Chem. Eur. J. 2004, 10, 28.

[2] H. A. Lowenstam, S. Weiner, On Biomineralization, Oxford University Press, New York, 1989.

[3] S. Mann, Biomineralization, Oxford University Press, Oxford, 2001.

[4] Biomineralization, Progress in Biology, Molecular Biology and Application, 2nd completely revised and extended ed. (Ed.: E. Bäuerlein), Wiley VCH, Weinheim, 2004.

[5] M. E. Marsh in Biomineralization, Progress in Biology, Molec ular Biology and Application, 2nd completely revised and extended ed., Wiley VCH, Weinheim, 2004, p. 197.

[6] G. Donnay, D. L. Pawson, Science 1969, 166, 1147.

[7] Y. Politi, T. Arad, E. Klein, S. Weiner, L. Addadi, Science 2004, 306, 1161.

[8] H. Cölfen, S. Mann, Angew. Chem. 2003, 115, 2452; Angew. Chem. Int. Ed. 2003, 42, 2350.

[9] G. Wegner, P. Baum, M. Müller, J. Norwig, K. Landfester, Macromol. Symp. 2001, 175.

[10] L. Qi, H. Cölfen, M. Antonietti, Angew. Chem. 2000, 112, 617; Angew. Chem. Int. Ed. 2000, 39, 604.

[11] A. Taubert, D. Palms, Q. Weiss, M. T. Piccini, D. N. Batchelder, Chem. Mater. 2002, 14, 2594.

[12] E. Matijevic, P. Schreiner, J. Colloid Interface Sci. 1978, 63, 509.

[13] W. P. Hsu, L. Rönnquist, E. Matijevic, Langmuir 1988, 4, 31.

[14] K. Yamada, S. Kohiki, Phys. E 1999, 228.

[15] S. Kohiki, S. Takada, A. Shimizu, K. Yamada, H. Higashijima, J. Appl. Phys. 2000, 87, 474.

[16] S. Kohiki, S. Takada, K. Yamada, Y. Adachi, A. Shimizu, M. Oku, M. Mitome, Phys. E 2000, 161.

[17] H. Higashijima, S. Kohiki, S. Takada, A. Shimizu, K. Yamada, Appl. Phys. Lett. 1999, 75, 3189.

[18] C. M. Soukoulis, Photonic Band Gap Materials, Kluwer, Boston, MA, 1996.

[19] C. B. Murray, C. R. Kagan, M. G. Bawendi, Science 1995, 270, 1335.

[20] C. P. Collier, T. Vossmeyer, J. R. Heath, Annu. Rev. Phys. Chem. 1998, 49, 271.

[21] C. B. Murray, C. R. Kagan, M. G. Bawendi, Annu. Rev. Mater. Sci. 2000, 30, 545 .

[22] C. B. Murray, S. H. Sun, W. Gaschler, H. Doyle, T. A. Betley, C. R. Kagan, IBM J. Res. Dev. 2001, 45, 47.

[23] H. Weller, Philos. Trans. R. Soc. Lond. A 2003, 361, 229.

[24] F. X. Redl, K. S. Cho, C. B. Murray, S. O. Brien, Nature 2003, 423, 968.

[25] T. Vossmeyer, G. Reck, L. Katsikas, E. T. K. Haupt, B. Schulz, H. Weller, Science 1995, 267, 1476.

[26] Y. Lu, Y. D. Yin, Y. N. Xia, Adv. Mater. 2001, 13, 415.

[27] E. Matijevic, J. Eur. Ceram. Soc. 1998, 18, 1357.

[28] J. J. Petres, G. Dezelic, B. Tezak, Croat. Chem. Acta 1969, 41, 183.

[29] S. H. Lee, Y. S. Her, E. Matijevic, J. Colloid Interface Sci. 1997, 186, 193.

[30] S. Wohlrab, N. Pinna, M. Antonietti, H. Cölfen, Chem. Eur. J. 2005, 11, 2903.

[31] Z. Zhang, H. Sun, X. Shao, D. Li, H. Yu, M. Han, Adv. Mater. 2005, 17, 42 .

[32] S. Dominguez Bella, J. M. Garcia Ruiz, J. Cryst. Growth 1986 , $79,236$.

[33] R. L. Penn, J. F. Banfield, Geochim. Cosmochim. Acta 1999, 63, 1549.

[34] J. Polleux, N. Pinna, M. Antonietti, M. Niederberger, Adv. Mater. 2004, 16, 436 .

[35] J. Polleux, N. Pinna, M. Antonietti, C. Hess, U. Wild, R. Schlögl, M. Niederberger, Chem. Eur. J., 2005, 11, 3541.

[36] L. Qi, H. Cölfen, M. Antonietti, M. Li, J. D. Hopwood, A. J. Ashley, S. Mann, Chem. Eur. J. 2001, 7, 3526.

[37] S. H. Yu, H. Cölfen, M. Antonietti, Chem. Eur. J. 2002, 8, 2937. 
[38] S. H. Yu, H. Cölfen, M. Antonietti, Adv. Mater. 2003, 15, 133.

[39] S. H. Yu, M. Antonietti, H. Cölfen, J. Hartmann, Nano Lett. 2003, 3, 379.

[40] J. F. Banfield, S. Welch, H. Zhang, T. Thomsen Ebert, R. L. Penn, Science 2000, 289, 751.

[41] M. Li, H. Schnablegger, S. Mann, Nature 1999, 402, 393.

[42] S. H. Yu, H. Cölfen, J. Mater. Chem. 2004, 14, 2124.

[43] H. Cölfen, Macromol. Rapid Commun. 2001, 22, 219.

[44] S. Busch, Dissertation, Technische Universität (Darmstadt), 1998.

[45] S. Busch, H. Dolhaine, A. DuChesne, S. Heinz, O. Hochrein, F. Laeri, O. Podebrad, U. Vietze, T. Weiland, R. Kniep, Eur. J. Inorg. Chem. 1999, 10, 1643.

[46] R. Kniep, S. Busch, Angew. Chem. 1996, 108, 2788; Angew. Chem. Int. Ed. Engl. 1996, 35, 2624.

[47] S. Busch, U. Schwarz, R. Kniep, Adv. Funct. Mater. 2003, 13, 189.

[48] R. Kniep in Facetten einer Wissenschaft (Eds.: A. Müller, H. J. Quadbeck Seeger, E. Diemann), Wiley VCH, Weinheim, 2004, p. 221.

[49] S. Busch, U. Schwarz, R. Kniep, Chem. Mater. 2001, 13, 3260.

[50] P. Simon, W. Carillo Cabrera, P. Formanek, C. Göbel, D. Geiger, R. Ramlau, H. Tlatlik, J. Buder, R. Kniep, J. Mater. Chem. 2004, 14, 2218 .

[51] C. A. Volkert, S. Busch, B. Heiland, G. Dehm, J. Microsc. 2004, $214,208$.

[52] A. Putnis, M. Prieto, L. Fernandez Diaz, Geol. Mag. 1995, 132, 1.

[53] O. Grassmann, R. B. Neder, A. Putnis, P. Löbmann, Am. Mineral. 2003, $88,647$.

[54] O. Grassmann, G. Müller, P. Löbmann, Chem. Mater. 2002, 14, 4530.

[55] O. Grassmann, P. Löbmann, Chem. Eur. J. 2003, 9, 1310.

[56] D. Shindo, G. S. Park, Y. Waseda, T. Sugimoto, J. Colloid Interface Sci. 1994, 168, 478.

[57] G. S. Park, D. Shindo, Y. Waseda, J. Electron Microsc. 1994, 43, 208.

[58] D. Shindo, S. Aita, G. S. Park, T. Sugimoto, Mater. Trans. JIM 1993, 24, 1226.

[59] G. S. Park, D. Shindo, Y. Waseda, T. Sugimoto, J. Colloid Interface Sci. 1996, 177, 198.

[60] K. Inumaru, H. Nakajima, T. Ito, M. Misono, Chem. Lett. 1996, 7, 559.

[61] T. Ito, I. K. Song, K. Inumaru, M. Misono, Chem. Lett. 1997, 8, 727.

[62] T. Ito, K. Inumaru, M. Misono, J. Phys. Chem. B 1997, 101, 9958.

[63] T. Ito, K. Inumaru, M. Misono, Chem. Lett. 2000, 11, 830.

[64] T. Ito, K. Inumaru, M. Misono, Chem. Mater. 2001, 13, 824.
[65] K. Inumaru, T. Ito, M. Misono, Microporous Mesoporous Mater. 1998, $21,629$.

[66] C. E. A. Kirschhock, R. Ravishankar, P. A. Jacobs, J. A. Martens, J. Phys. Chem. B 1999, 103, 11021.

[67] C. E. A. Kirschhock, V. Buschmann, S. Kremer, R. Ravishankar, C. J. Y. Houssin, B. L. Mojet, R. A. van Santen, P. J. Grobet, P. A. Jacobs, J. A. Martens, Angew. Chem. 2001, 113, 2707; Angew. Chem. Int. Ed. 2001, 40, 2637.

[68] N. Jongen, J. Lemaitre, P. Bowen, H. Hofmann, Proceedings of 5th World Congress of Chemical Engineering, San Diego, 1996, pp. 31.

[69] N. Jongen, P. Bowen, J. Lemaitre, J. C. Valmalette, H. Hofmann, J. Colloid Interface Sci. 2000, 226, 189.

[70] N. Jongen, H. Hofmann, P. Bowen, J. Lemaitre, J. Mater. Sci. Lett. 2000, 19, 1073.

[71] L. C. Soare, P. Bowen, J. Lemaitre, H. Hofmann, M. Pijolat, F. Valdivieso, Materials Research Society Symposium Proceedings. Proceedings of 2003 MRS Fall Meeting, Boston, MA, 2003, p. L1.4.

[72] L. C. Soare, PhD thesis 3083, Ecole Polytechnique Federale de Lausanne, 2004.

[73] O. Pujol, P. Bowen, P. A. Stadelmann, H. Hofmann, J. Phys. Chem. B 2004, 108, 13128.

[74] T. X. Wang, H. Cölfen, M. Antonietti, J. Am. Chem. Soc. 2005, $127,3246$.

[75] I. Sethmann, A. Putnis, O. Grassmann, P. Löbmann, American Mineralogist 2005, 90, 1213.

[76] A. Taden, K. Landfester, M. Antonietti, Langmuir 2004, $20,957$.

[77] B. Judat, M. Kind, J. Colloid Interface Sci. 2004, 269, 341.

[78] J. Rieger, D. Franke, T. Frechen, H. Haberkorn, W. Goesele, Proceedings BIWIC. Proceedings of 9th Workshop on Industrial Crystallization, Halle Wittenberg, 2002, p. 13.

[79] "Zur Theorie des Kristallwachstums": W. Kossel, Nachr. Ges. Wiss. Goettingen Math. Phys. Kl. 1927, 135.

[80] I. N. Stranski, Z. Phys. Chem. A 1928, 136, 259.

[81] W. K. Burton, N. Cabrera, F. C. Frank, Philos. Trans. R. Soc. Lond. A 1951, 243, 299.

[82] A. P. Alivisatos, Science 2000, 289, 736.

[83] R. Agra, F. van Wijland, E. Trizac, Phys. Rev. Lett. 2004, 93, 018301.

[84] S. H. Yu, H. Cölfen, K. Tauer, M. Antonietti, Nat. Mater. 2005, 4, 51.

[85] Y. Oaki, H. Imai, Angew. Chem. 2004, 116, 1387; Angew. Chem. Int. Ed. 2004, 43, 1363.

[86] Y. Oaki, H. Imai, Langmuir 2005, 21, 863.

[87] Y. Oaki, H. Imai, J. Am. Chem. Soc. 2004, 126, 9271. 